\title{
Simon and Garner effects with color and location: Evidence for two independent routes by which irrelevant location influences performance
}

\author{
Daniel Fitousi ${ }^{1}$
}

Published online: 1 September 2016

(C) The Psychonomic Society, Inc. 2016

\begin{abstract}
Classic theories of attention assume that the processing of a target's featural dimension (e.g., color) is contingent on the processing of its spatial location. The present study challenges this maxim. Three experiments evaluated the dimensional independence of spatial location and color using a combined Simon (Simon \& Rudell Journal of Applied Psychology: 51, 300-304, 1967) and Garner (Garner, 1974) design. The results showed that when the stimulus's spatial location was rendered more discriminable than its color (Experiment 1 and 2), both Simon and Garner effects were obtained, and location interfered with color judgments to a larger extent than color intruded on location. However, when baseline discriminabilities of location and color were matched (Experiment 3), no Garner interference was obtained from location to color, yet Simon effects still emerged, proving resilient to manipulations of discriminability. Further correlational and distributional analyses showed that Garner and Simon effects have dissociable effects. A triple-route model is proposed to account for the results, according to which irrelevant location can influence performance via two independent location routes/codes.
\end{abstract}

Keywords Spatial location $\cdot$ Garner interference $\cdot$ Simon effects

Every stimulus in our environmental milieu occupies a unique spatial location. It is almost impossible to imagine a stimulus which is devoid of location. This seemingly undisputed fact has led many attention theorists to endow spatial location with

Daniel Fitousi

danielfi@ariel.ac.il

1 Department of Behavioral Science, Ariel University, Ariel, Israel a privileged status (Eriksen \& Eriksen, 1974; Posner, 1980; Treisman \& Gelade, 1980; Wolfe, 1994). According to this view, the processing of a target's nonspatial attribute, such as its color, is contingent on the processing of its spatial location (Johnston \& Pashler, 1990; Tsal \& Lavie, 1993). One of the most impressive sources of evidence in favor of the primacy of spatial location over nonspatial attributes comes from the Simon task (Simon \& Rudell, 1969). In this paradigm, participants are asked to judge a certain nonspatial attribute of a target (e.g., color) by pressing one of two lateralized keys. The target appears either to the left or to the right of the fixation point. Responses are faster and more accurate if the location of the response is congruent with the target's location (e.g., a right-hand response to a target on the right-side of space) in comparison to a condition in which the target's spatial location is incongruent with the response-key location (e.g., a right-hand key press to a target on the left-side of space).

This Simon effect (Hedge \& Marsh, 1975; Hommel, 1993a, 1993b; Simon, 1969; Simon, Hinrichs, \& Craft, 1970; Kornblum, 1994; Simon \& Rudell, 1967; Simon \& Small, 1969; Treccani, Umiltà, \& Tagliabue, 2006; Umiltà, 2004; Vale-Inclan, Hackley, \& De Labra, 2003; Wallace, 1971; Wühr, 2006; Wühr, \& Ansorge, 2005) documents the interesting result that participants' performance is inadvertently affected by the target's spatial location, even when location is irrelevant for the task at hand, or when it hampers performance. The Simon effect supports the deeply rooted belief that processing of nonspatial attributes is contingent on the processing of spatial location. However, a recent series of neurophysiological studies on the relations between feature-based and space-based attention (Hopf, Boelmans, Schoenfeld, Luck, \& Heinze, 2004; Treue \& Trujillo, 1999; Zhang \& Luck, 2009) has shown that attention to nonspatial features (e.g., color) operates independently of attention to spatial 
location. This line of research invites a novel examination of the alleged dependency between spatial and nonspatial attributes in the Simon task as well as in other related tasks.

The goal of the present study has been to elucidate the dimensional relations ensuing between spatial location and nonspatial attributes. This has been accomplished through the application of a classic selective attention tool-the Garner speeded classification task (Garner, 1974) - to the dimensions of location and color. The Garner paradigm (for a review see Algom, \& Fitousi, 2016) affords the assessment of the level of independence (or its lack thereof) in the processing of two dimensions or attributes that do not necessarily convey semantic or response conflict (Algom \& Fitousi, 2016; Fitousi, 2015; Fitousi, Shaki \& Algom, 2009; Garner, 1974; Garner \& Felfoldy, 1970). This property makes the Garner speeded classification task, of all available selective attention paradigms (i.e., Stroop, flanker), a device of the broadest applicability; it is especially instrumental in the case of color and spatial location, dimensions that do not bear any a priori inherent response or semantic conflict. Another marked advantage of the Garner paradigm is that it permits the measurement of the Simon effect within the Garner design.

The current investigation underscored both Garner and Simon effects with color and spatial location. The Garner effects showed that location intruded on color judgments more than did color on spatial location classifications. However, this held true only under conditions in which the dimensional salience of location was rendered superior to that of color. When the dimensional discriminability of location was matched to that of color (Melara \& Mounts, 1993), such that overall processing speeds of location and that of color were equated, Garner interference from location to color was eliminated, whereas Simon effects remained unaffected. Augmented by further correlational and distributional analyses, these results supported the conclusion that spatial location is processed via two independent routes/loci. In the first route-which is probed by the Garner interference-location is selected at an early selection stage, whereas in the second route-which is gauged by the Simon effect-location is selected at a late response stage. The results bear implications for theories of spatial attention as well as for theorizing on the Simon and Garner effects.

\section{The Simon effect}

The Simon task has attracted much attention from researchers (for reviews see Lu \& Proctor, 1995; Hommel, 2011). Its considerable appeal has been often ascribed to its utility as both "a heuristic and a tool" (Hommel, 2011, p.189). Four central accounts have been proposed to explain the Simon effect. The first is an attentional account (Nicoletti \& Umiltá 1989, 1994). According to this explanation, shifting attention to a stimulus invokes a spatial code that can either conflict or agree with the response code. This explanation is tangential to the premotor theory of attention (Rizzolatti, Riggio, Dascola, \& Umiltà, 1987), which postulates that moving attention along the visual space requires the programing of eye movements. A second account is based on the idea of feature overlap (e.g., Kornblum, Hasbroucq, \& Osman, 1990; Kornblum, Stevens, Whipple, \& Requin, 1999; O Leary \& Barber, 1993; Zorzi \& Umiltá 1995). According to this account, response features can match or mismatch with stimulus features, an overlap that leads to stimulus-response compatibility effects. The third account has been suggested by Hommel (2011), and is dubbed here "action integration." The basic idea can be dated back to the ideomotor theory (James, 1890; Harless, 1861; Lotze, 1852), according to which, actions are learned and represented as sensorymotor bindings. Because certain actions codes anticipate the emergence of certain perceptual attributes, actions influence response selection stages (Elsner \& Hommel, 2001; Hommel, 1993a). The fourth explanation is a relative speed of processing account (Hommel, 1993b), according to which spatial location is processed faster than nonspatial attributes, and therefore interferes with it. This account is most prominent in dual-route models to which the next section is dedicated.

\section{Dual-route models}

Researchers have proposed several processing architectures that may generate the Simon effect (Lu \& Proctor, 1995). A popular proposal is instantiated in a class of dual-process models (De Jong et al., 1994; Wascher, Schatz, Kuder, \& Verleger, 2001; see also Frith \& Done, 1986; Kornblum et al., 1990; Sanders, 1967; Ridderinkhof, 2002a, 2002b; Tagliabue, Zorzi, Umilta, \& Bassignani, 2000). The models postulate the existence of two interacting processing routes: an automatic (unconditional) path and an intentional (conditional) path. The automatic path operates rapidly, encoding and activating the spatial location representation; the controlled route is slower and voluntary, and is responsible for the processing of the relevant featural dimension (e.g., color) by executing the task instructions. A common assumption made in dual-process models is that spatial location activates mandatory long-term, possibly innate (Zorzi \& Umiltá 1995), stimulus-location-response tendencies (Sokolov, 1963), which in turn prime response on the voluntary route. This priming enhances performance with the relevant dimension in congruent trials, but hampers performance in incongruent trials.

There is now substantial evidence to support models of dual-route architecture (Zorzi \& Umiltá, 1995). These models assume that the automatic (location) route exerts 
its influence at an early stage, while the controlled (color) route operates at later stages. This alleged asymmetry predicts a dissipation of the Simon effect with time, a prediction that has been tested and validated (De Jong et al., 1994; Ridderinkhof, 2002a, but see Zhang and Kornblum, 1997). A second source of support in dual-route architectures comes from a delayed response procedure (Simon, Acosta, Mewaldt, \& Speidel, 1976). In this methodology, participants are asked to delay their response to a visual stimulus until they hear a tone. The tone can appear in various delays after the stimuli (i.e., $0 \mathrm{~ms}, 150 \mathrm{~ms}$, $250 \mathrm{~ms}$, or $350 \mathrm{~ms}$ ). The Simon effect is often eradicated for the longer two delays (Burle, van den Wildeberg \& Ridderinkhof, 2005; Vallesi \& Umiltà 2009; but see Ivanoff, 2003). These results suggest that the interference from irrelevant (automatic) spatial location is present at an early stage, but that it decreases gradually at later processing stages, as control operations take over. A third line of support arrives from studies that set to manipulate the temporal correspondence between the fast and slow routes. A direct prediction of dual-route models is that the size of the Simon effect should be related to the degree of temporal overlap between the automatic and controlled routes. In line with this prediction, it has been shown that slowing down the processing time of the relevant-attribute task leads to a reduction (Hommel, 1993a; Roswarski \& Proctor, 1996), or even a complete abolishment (Hommel, 1994) of the Simon effect. A fourth line of support for dual-route models comes from event-related potential (ERP) studies of the lateralized readiness potential (LRP) - a measure of the average asymmetry in ERPs over left and right primary motor cortex. De Jong et al. (1994) found that on congruent trials, the LRP reached its amplitude at $170 \mathrm{~ms}$ after stimulus onset, whereas in incongruent trials an initial asymmetry corresponding to the wrong choice was present within the same time window.

It is important to acknowledge that there are several lines of evidence that run counter to the dual-route model. First, Valle-Inclan and Redondo (1998) found that early activation of the spatially corresponding response in the LRP did only occur when participants knew the S-R rules before stimulus onset, but not when the imperative stimulus (conveying the irrelevant location information) occurred before participants were informed about the S-R mapping. Secondly, Ansorge and Wühr (2009) found that Simon effects occurred in a go/no-go task (involving correspondence and non-correspondence between stimulus and response locations) when participants did a similar two-choice task before, but there was no Simon effect in the go/no-go task when this task was performed first. Finally, several studies showed that working-memory (WM) load can reduce, and sometimes even eliminate,
Simon effects (e.g., Wühr \& Biebl, 2011). These studies cast doubt on the validity of the dual-route model.

\section{Is color contingent on location?}

Traditional interpretations of the Simon effect mandate that the processing of featural attributes (e.g., color or shape) depends on the activation of spatial location (De Jong et al., 1994). This dependency has been often attributed to either an innate tendency to process location first (Zorzi \& Umiltá 1995), an initial creation of a spatial code due to an attentional shift (Hillyard \& Münte 1984), or the relatively faster speed of processing of location in comparison to that of color or shape (De Jong et al., 1994). The idea that a stimulus's spatial location precedes its nonspatial attributes is also consensual outside the Simon effect realm in other quarters of the attention research. Many researchers have claimed that attentional selection of relevant information eventually occurs on the basis of spatial location. Support in this claim comes from behavioral (Posner, 1980; Tsal \& Lavie, 1993) and ERP (AnlloVento \& Hillyard 1996; Eimer, 1995; Hillyard \& Münte 1984) studies.

In a pair of influential studies, Tsal and Lavie, (1988, 1993, see also Tsal \& Lamy, 2000) provided behavioral evidence in favor of the "location-precedence hypothesis." In one study (Tsal \& Lavie, 1988), they asked participants to report a colored letter that appeared among other letters. The results indicated that the additional letters reported tended to be adjacent to the first reported target. In another study (Tsal \& Lavie, 1993), participants were asked to report the letter in a cued position. Participants reported letters adjunct to the cue and not those similar to its color or shape. The results entailed that the selective processing of targets specified by color or by shape is accomplished by attending to the targets' locations (see also Johnston \& Pashler, 1990). In a similar vein, ERPs studies showed that spatial attention enhances the amplitude of the sensory-evoked P1 component within $100 \mathrm{~ms}$ of stimulus onset, whereas feature-based attention occurs later, between 150 and 300 ms post-stimulus (Anllo-Vento \& Hillyard 1996; Hillyard \& Münte 1984). These feature-based attention effects are abolished for stimuli presented at unattended location (Hillyard \& Münte 1984).

Recently, Zhang and Luck (2009) have argued that most ERP studies of feature-based attention that supported the "location-precedence hypothesis" have typically presented the attended and ignored features one at a time. This minimized direct competition between feature-based and spacebased attention. Zhang and Luck (2009) conjectured that if feature information is presented at the attended and ignored location simultaneously, featural attention would be able to influence the processing of spatial information. This conjecture has been validated, leading Zhang and Luck to the 
conclusion that "color-based attention can influence the flow of feedforward sensory information within $100 \mathrm{~ms}$ of stimulus onset, even for stimuli presented at an unattended location" (p. 25). Moreover, "under conditions of simultaneous competition, color based attention operates throughout the visual field in a global manner, independently of spatial attention" (p.25). These results are important because they challenge the dominant view that spatial location precedes featural information. Zhang and Luck's (2009) results may have immediate implications for understanding the influence of irrelevant location on color judgments in the Simon as well as in other related tasks. Their results propose that when color (or any other featural information) is given fair chance of competition, it can, in principle, be processed independently of spatial location, and may even influence the processing of location. An unfair competition between color and location might explain the results of behavioral studies (e.g., Tsal \& Lavie, 1993), including Simon studies (Simon \& Rudell, 1967), in which the location dimension was rendered, by default, a more discriminable or salient attribute to perception than the nonspatial attribute (i.e., color, shape).

A most suitable paradigm for testing Zhang and Luck's (2009) hypothesis regarding the dimensional independence of spatial location and color is afforded by Garner's speeded classification task (Garner, 1974; for review see Algom \& Fitousi, 2016). Since its inception some 50 years ago (Garner, 1969, 1970, 1974, 1976; Garner \& Felfoldy, 1970; Gottwald \& Garner, 1972, 1975; Handel \& Imai, 1972; Hyman \& Well, 1967, 1968; Imai, 1966; Imai \& Garner, 1965; Lockhead, 1966, 1972), the test and its attendant concepts have been well established in cognitive science. Garner interference serves as the primary procedure for assessing selectivity and independence (Algom \& Fitousi, 2016; Algom et al., 1996; Fitousi, 2015; Fitousi et al., 2009; Fitousi \& Wenger, 2013; Melara \& Marks, 1990; Melara \& Mounts, 1993; Pansky \& Algom 1999; Pomerantz, 1983, 1991; Pomerantz \& Garner, 1973; Van Leeuwen \& Bakker, 1995).

\section{Garner interference with spatial location and color}

Consider an experimental set up in which a target is presented to you in one of two possible colors (e.g., red, green) at one of two spatial locations (e.g., left, right). Your task is to classify the color of the target while ignoring its spatial location. The Garner logic is straightforward (Algom \& Fitousi, 2016). In one block of trials, the experimenter keeps the task-irrelevant dimension of location constant, so that only the target's color varies from trial-to-trial (Baseline). In another block of trials, the experimenter lets the task-irrelevant location vary randomly (Filtering). The task for the participant is the same in both blocks of trials: to classify color as speedily and accurately as possible. The difference in performance between the two conditions reveals the success of selective attention to color. Poorer performance in Filtering than in Baseline would indicate that irrelevant variation in location took a toll on performance, compromising fully selective attention to color. Alternatively, similar performance in the two conditions would indicate that irrelevant location was successfully filtered out. Comparable performance in Filtering and Baseline points to perfect selectivity of attention to the target color in spite of irrelevant variation on values of the target's spatial location. The difference in reaction time to classify color in the two blocks defines the measure known as Garner interference (Pomerantz, 1983; see also Algom \& Fitousi, 2016).

A third condition in the Garner paradigm is dubbed Correlation. In this condition, irrelevant location also varies from trial to trial. However, under Correlation it does so in a corresponding manner with the target dimension of color. For example, on all (most) trials, a green target appears on the left-side or vice versa. Performance under Correlation is often better than that in Baseline, the difference is called redundancy gain. This is because the irrelevant dimension of location now becomes predictive of the relevant dimension of color. Note, though, that the presence of redundancy gain also signals the failure of fully selective attention to color. In other cases, performance under Correlation can be on a par with that in Baseline, attesting to good selective performance with respect to target color. Note that when the dimensions convey the quality of congruency, such as the S-R congruency measured in the Simon task, the correlated blocks can be separated to positively (i.e., response location to color matches stimulus location) and negatively correlated blocks (i.e., response location is opposite to stimulus location). Redundancy gain is then computed as the difference between performance in baseline and in positively correlated blocks, whereas redundancy loss is computed as a difference between performance in the negatively correlated block and in baseline.

Garner's speeded classification paradigm has been applied to a large variety of perceptual dimensions (for a review see Algom \& Fitousi, 2016). Two general patterns of performance have been observed. For separable dimensions, such as color and shape (Garner, 1974), performance is uniform in Baseline, Filtering, and Correlation. With such dimensions, the participants neither suffer Garner interference nor reap redundancy gain. For integral dimensions, such as hue and saturation (Garner \& Felfoldy, 1970; Little, Wang, \& Nosofsky, 2016), performance is best under Correlation and worst in Filtering. With such dimensions, the participants suffer Garner interference from orthogonal variation in Filtering but reap redundancy gain from corresponding variation under Correlation. The question of interest in this study 
is whether spatial location and color are integral or separable dimensions.

\section{Garner and Simon measures}

Like the Simon effect, Garner interference reflects a failure of selective attention. The two are separate indicators of selective attention in the face of irrelevant variation on spatial location. Yet, both can be measured under the same experimental context (see Melara, Wang, Vu, \& Proctor, 2008). The Simon effect is probed by comparing performance in congruent (the location of the response and that of the stimulus corresponds) and in incongruent (the location of the response and that of the stimulus do not correspond) conditions. Three measures of Simon effects ensue. First, in the filtering condition of the Garner paradigm, the irrelevant (i.e., location) and relevant (i.e., color) are varied orthogonally. Hence, on half of the trials, spatial location corresponds to response location, while on the other half they conflict. These measures can serve to assess Simon effect within (Melara et al., 2008), and independently of (Garner, 1974) the Garner paradigm. A third measure of Simon effect stems from the correlated task. This measure is defined as the difference in performance between negatively and positively correlated dimensions.

\section{The present experiments}

I recounted the considerable evidence for the inadvertent influence of location on the processing of nonspatial attributes in the Simon task as well as in other attentional tasks. This evidence supports the "location precedence hypothesis", the hypothesis that featural information is always processed after spatial location, and therefore depends on it. This idea has been recently challenged by Zhang and Luck (2009) in a study on feature-based attention. They have shown that when location and color are processed at the same time, they appear as independent dimensions. In earlier studies on the processing of location and color baseline discriminabilities have not been taken into account. Information on discriminability is indispensable. In particular, the emergence of the Simon effect, or any other attentional effect that involves location and color, might depend on an asymmetry in baseline discriminability. Matching discriminability may render the dimensions separable and eliminate Garner or/and Simon effects completely (for the related case of Stroop and Garner, see Algom et al., 1996; Fitousi \& Algom, 2006; Melara \& Algom, 2003; Melara \& Mounts, 1993; Shalev \& Algom, 2000; see also Garner \& Felfoldy, 1970; Pomerantz, 1983). When Melara and Mounts (1993) matched the discriminability on the Stroop dimensions of word and color, the dimensions were found to be separable. Traditional Stroop and Garner effects surfaced only when the dimensions' salience mismatched, with the more discriminable dimension disrupting classification on the less discriminable dimension (see also Algom \& Fitousi, 2016; Algom et al., 1996; Fitousi \& Algom, 2006; Sabri, Melara, \& Algom, 2001). The goal of the present study was to explore the separability (or integrality) of spatial location and color by evaluating selective attention to spatial and featural dimensions. The experiments assessed the dimensional interaction between spatial location and color, harnessing both Garner and Simon measures.

\section{Experiment 1}

The aim of the first experiment was to gauge the traditional Simon effect in judgments of color (Hedge \& Marsh, 1975), using the full Garner speeded classification task (i.e., baseline, filtering, and correlated dimensions tasks). The psychophysical values of the stimuli used in Experiment 1 (e.g., distance from fixation, the very presence of a fixation point) were similar to those employed in the majority of Simon studies. It is expected that these psychophysical values should render the discriminability of the location dimension superior to that of color. It is therefore predicted that under this mismatched discriminability (Algom \& Fitousi, 2016; Fitousi \& Algom, 2006; Garner \& Felfoldy, 1970; Melara \& Mounts, 1993), irrelevant location would interfere with color judgments, but that color would not interfere with classification of location. This experiment can provide insights into the dimensional interaction of color and location, and into the role played by relative dimensional salience in determining their perceptual independence.

\section{Methods}

\section{Participants}

Sixteen undergraduate students from Ariel University participated. They received course credit for their participation. All observers reported normal or corrected-to-normal vision.

\section{Stimuli}

Stimuli were small red and green square shapes appearing over a white background. A black dot was used as a fixation point. Viewed at a fixed distance of $76 \mathrm{~cm}$, each shape subtended $0.6^{\circ}$ of visual angle, horizontally, and $0.6^{\circ}$ vertically. The fixation point subtended $0.20^{\circ}$ of visual angle, horizontally, and $0.20^{\circ}$ vertically. The green or red square shapes could appear either to the left or to the right of the fixation point. The distance between the shape and the fixation point was $2.26^{\circ}$. 


\section{Procedure and design}

Each trial started with a fixation point that remained on the screen until the termination of the trial (i.e., until response). After a period of $200 \mathrm{~ms}$ from the beginning of the trial, a colored square (red or green) was presented at one of two possible spatial locations on the screen (left or right side of fixation, see top panel of Fig. 1). A 500-ms inter-trial-interval was used. Each participant engaged in two types of tasks. In a color judgment task, participants indicated the color of the target by pressing one of two keys ("m" or " $\mathrm{z}$ "). In a location judgment task, participants classified the spatial location of the target by pressing one of two keys (" $\mathrm{m}$ " or " $\mathrm{z}$ "). Note that response mapping in the location judgment task was always compatible with the side of the target's location, that is a right- hand key ("m") was assigned to targets on the right, and a lefthand key (" $z$ ") was assigned to targets on the left. Each task (color, location) was performed separately. Order of tasks was randomized by the computer. Each task (color, location) consisted of five types of blocks: two Baseline blocks, one Filtering block, and two Correlation blocks. In the Baseline blocks, participants judged the relevant dimension (e.g., color) while the level of the irrelevant dimension (e.g., spatial location) was held constant at one value (e.g. left). Consider for example the color judgment task. In one baseline the target was always presented on the left side of the fixation point; in the second baseline the target was always presented on the right side of the fixation point. A similar logic applies to the baseline conditions of the location judgment task; in one baseline the target's color was always green, whereas in the other
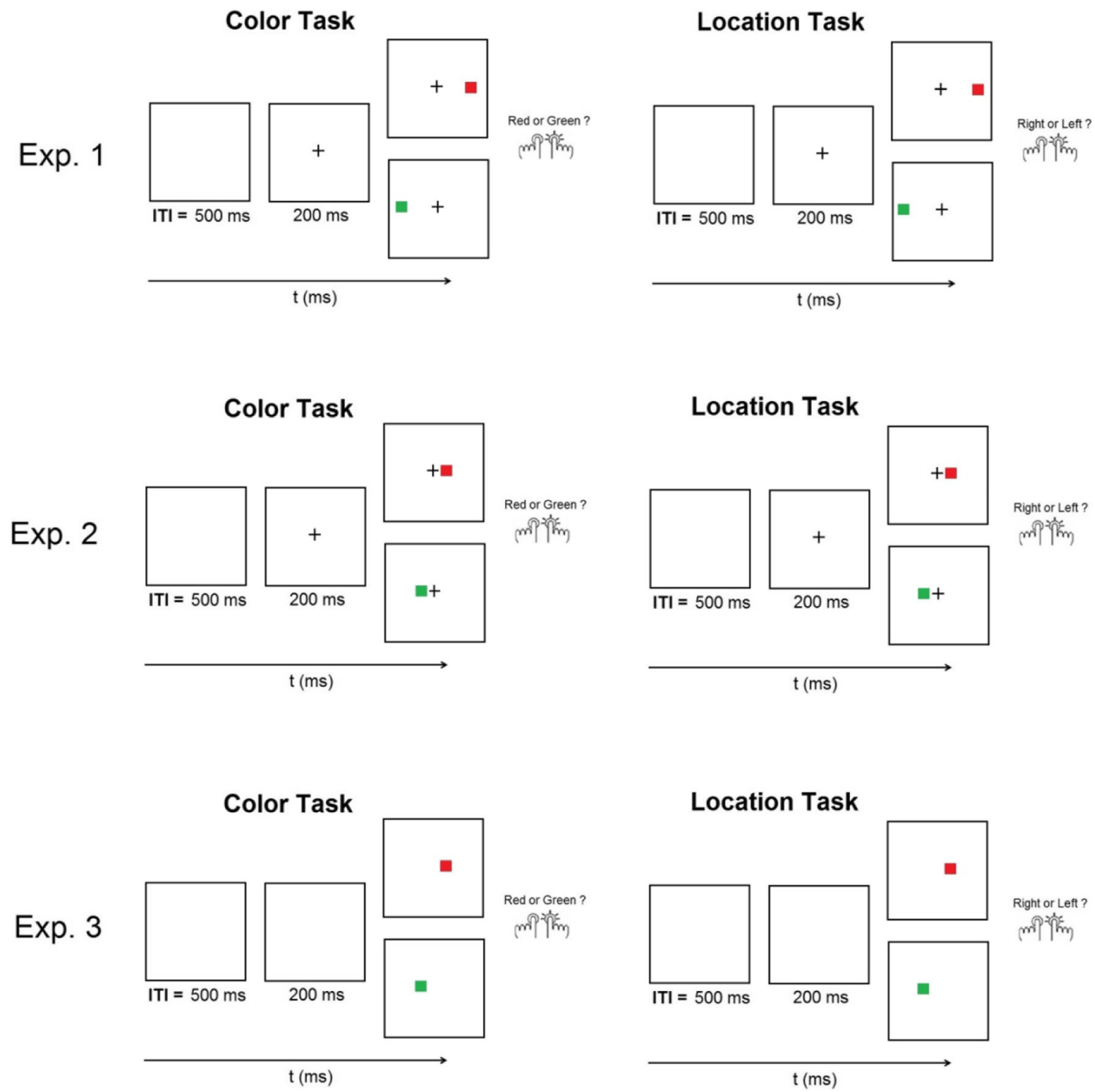

Fig. 1 Structure of a typical trial in Experiments 1-3. Each experiment consisted of a color task and location task. Top panel: Experiment 1, intermediate panel: Experiment 2, bottom panel: Experiment 3. ITI inter trial interval, $t$ time, $m s$ milliseconds 
baseline the target's color was always red. These baseline blocks did not include trial-to-trial variability on the irrelevant (color) dimension.

In the filtering blocks, the irrelevant dimension (e.g., location) varied from trial-to-trial in an orthogonal fashion. Thus, in the color task, the target's spatial location could appear either to the left or to the right of the fixation point, such that the target's spatial location was unpredictable. In the location task, the target's color was also unpredictable, and it could be either red or green. In addition, two baseline blocks were used in each task. For the color judgment task, the baselines consisted of a left-target baseline and a right-target baseline; in the former, the target could appear only on the left side of fixation, and in the latter, the target could show up only on the right side of fixation. For the location judgment task, the baselines consisted of a red-target baseline block, and green-target baseline block. In these baselines the color of the target was confined to a single color.

There were also two correlation blocks in which the values of relevant (e.g., color) and irrelevant (e.g., location) dimensions always varied together. That is, the level of one dimension, say red color, was always presented with the same level of spatial location, say the left side, and vice versa. In the color judgment task, this dictates two types of correlated blocks. A positively correlated block $(\mathrm{C}+)$ is a block in which the location of the target (e.g., left, right) is always congruent with the side of the color judgment's response, in the same sense of congruency in a Simon trial (Hommel, 2011). A negatively correlated block (C-) is a block in which the spatial location of the target is always opposite to that required by the color judgment response, and therefore it is incongruent, in the same sense as a incongruent Simon trial. The distinction between positively and negatively correlated blocks is meaningless for the location judgment task because the relevant dimensionspatial location-does not convey the quality of congruency between side of response and color (red, green). There is nothing congruent or incongruent in a left-hand response to a red target.

The distinction made here between positively and negatively correlated blocks is important for two main reasons. First, it allows measuring two different species of redundancy effects in the Garner task: (1) redundancy gains and (2) redundancy losses (Melara \& Mounts, 1993; Melara \& Algom, 2003). The former is computed as the difference between mean reaction time (RT) in baseline and mean RT in positively correlated blocks. The latter is computed as the difference between mean $\mathrm{RT}$ in the negatively correlated block and mean RT in baseline. A redundancy gain implies that participants reaped gain due to the positive correspondence between the dimensions. A redundancy loss implies that participants' performance suffered due to the mismatch between the two dimensions. A second reason for keeping the distinction between positively and negatively correlated block has to do with the Simon task (Simon
\& Rudell, 1969). Note that trials in the positively correlated block are also Simon congruent trials, whereas trials in the negatively correlated block are also Simon incongruent trials. This means that the difference between performance measures in the negatively correlated block (i.e., $\mathrm{C}$-) and positively correlated block (i.e., $\mathrm{C}+$ ) provides an across-block measure of the Simon effect.

The experiment was designed as two (task: color, location) $\times 5$ (block type: filtering, baseline 1 , baseline 2 , correlation 1, correlation 2) full factorial within-participants design. The dependent variables were mean RTs and percentages of error rates. All trials were initiated by the computer. The stimuli were presented with equal frequency in each block of trials. Each observer completed three identical cycles of color and location judgment blocks. Order of tasks (color, location) was randomized by the computer. Order of blocks (filtering, correlated, baseline) was also randomized with subtypes of correlated and baseline blocks performed sequentially (Fitousi et al., 2009; Pansky \& Algom, 1999). Each filtering block consisted of 52 trials, whereas each baseline or correlated block consisted of 26 trials. Every participant completed 936 trials. Unbeknownst to the participants, the first ten trials were considered as training, and were deleted from data analysis.

\section{Results}

\section{Garner effects}

Trials with RTs shorter than $150 \mathrm{~ms}$ or RTs longer than 2,500 ms (1.2\%) were excluded from analysis. Trials with incorrect responses $(4.4 \%)$ were also removed. Figure 2 presents mean RTs and error rates in Experiment 1. Classification of spatial location (318 ms) was $106 \mathrm{~ms}$ faster than classification of color $(424 \mathrm{~ms})\left[F(1,15)=174.8, p<0.0000001, \eta_{p}^{2}=\right.$ 0.92], revealing an acute imbalance in the dimensional salience of the two attributes. Another test of relative dimensional salience can be made by comparing performance in the baseline block (after averaging the two baselines) of each task (Algom \& Fitousi, 2016; Fitousi \& Wenger, 2013; Melara \& Marks, 1990). Indeed, performance in the location baseline (310 ms) was $124 \mathrm{~ms}$ faster than performance in the color baseline (434 ms) $[t(1,15)=11.74, p<0.00000001, d=1.66]$. These results confirm the initial hypothesis that spatial location is, by far, a more salient dimension for perception than color. As for performance in each of the tasks, consider first judgments of color. Performance in the two baselines $(448 \mathrm{~ms}$, $428 \mathrm{~ms})$ was on $\operatorname{par}\left[F(1,15)=1.34, p=0.25, \eta_{p}^{2}=0.02\right]$, and they were merged into a single baseline. A 56-ms Garner interference ( $490 \mathrm{~ms}$ in filtering versus $434 \mathrm{~ms}$ in baseline) $\left[F(1,15)=23.28, p<0.00001, \eta_{p}^{2}=0.34\right]$, entailed that, while judging color, participants suffered from the trial-to-trial irrelevant variation on spatial location. In addition, participants 


\section{Garner Effects}

Experiment 1

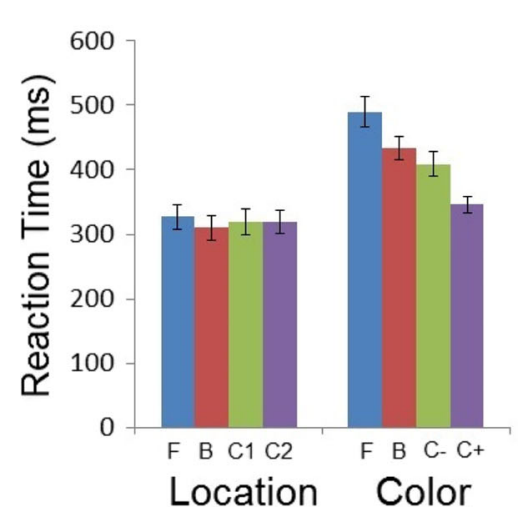

Fig. 2 Experiment 1, Garner effects in judgments of color and location for mean reaction time (left panel) and percentage of error rates (right panel). Location location task, Color color task, ms milliseconds, $F$

reaped a $88-\mathrm{ms}$ redundancy gain $(346 \mathrm{~ms}$ in the $\mathrm{C}+$ and $434 \mathrm{~ms}$ in baseline) due to the positive correlation between color and location $[F(1,15)=122.97, p<0.00001$, $\left.\eta_{p}^{2}=0.73\right]$. No redundancy loss has been obtained, as performance in the C- block (409 ms) was not slower than that in baseline $(434 \mathrm{~ms})[F<1]$.

Next consider judgments of spatial location. A small Garner interference of $17 \mathrm{~ms}$ was indicated by a significant difference between performance in filtering $(327 \mathrm{~ms})$ and baseline $(310 \mathrm{~ms})\left[F(1,15)=5.7, p<0.05, \eta_{p}^{2}=0.11\right]$. This result suggests that judgments of location were interfered by irrelevant variation on color. Note that the Garner interference from color to location was smaller than the Garner interference from location to color, as suggested by a significant interaction between the type of task (color vs location) and Garner block (filtering vs baseline) $[F(1,15)=13.43$, $\left.p<0.005, \eta_{p}^{2}=0.47\right]$. As for the correlated blocks, recall that the sign of the correlation blocks in classification of location is meaningless, because the quality of S-R correspondence does not apply in this type of judgments. Thus, the two blocks were merged into a single correlation block. Performance in baseline $(310 \mathrm{~ms})$ and in correlation $(320 \mathrm{~ms})$ was on $\operatorname{par}[F<1]$, suggesting the absence of a redundancy effect in judgments of location.

Analyses on error rates revealed comparable patterns to those obtained with RTs, although the effects were less pronounced. As in the RT data, location was more discriminable $(1.5 \%)$ than location $(4.8 \%)[F(1,15)=35.85, p<0.000001$, $\left.\left.\eta_{p}^{2}=0.80\right)\right]$. A test of the baseline blocks revealed lower error rates and therefore a better discriminability, in the location baseline $(2.06 \%)$ than in the color baseline $(5.8 \%)$ $[t(15)=5.81, p<0.000001, d=1.10]$. Consider first judgments of color. A numerical Garner interference obtained, as more errors were made in filtering $(7.2 \%)$ than in baseline

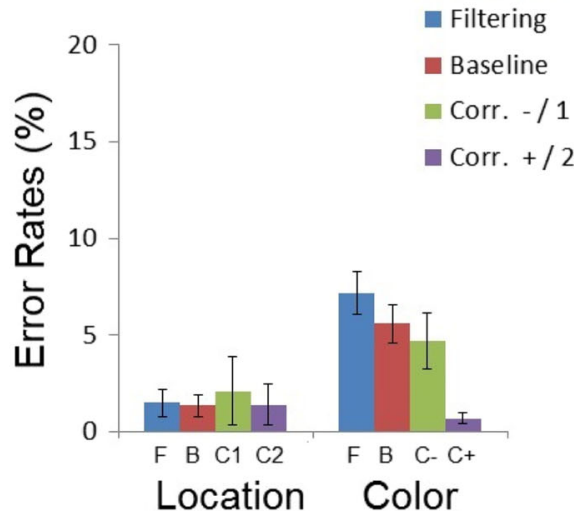

filtering, $B$ baseline, $C+$ positively correlated, $C$ - negatively correlated, $C 1$ correlated 1, $C 2$ correlated 2. Error bars are standard error of the mean

(5.6\%), but the effect did not approach significance level $\left.\left[F(1,15)=2.46, p=0.12, \eta_{p}^{2}=0.03\right)\right]$. A large redundancy gain was evident, with more errors being made in baseline $(5.6 \%)$ than in the positively correlated block $(0.70 \%)$ $\left.\left[F(1,15)=45.5, p<0.0000001, \eta_{p}^{2}=0.50\right)\right]$. No redundancy loss has been recorded, as the error rates in negatively correlated blocks $(4.70 \%)$ were not larger than those in baseline $\left.(5.6 \%)\left[F(1,15)=1.02, p=0.31, \eta_{p}^{2}=0.02\right)\right]$. As for judgments of spatial location, no Garner interference was obtained, as performance in filtering and baseline was comparable $(1.50 \%$ vs $1.37 \%)[F<1]$. No redundancy effect obtained either, as performance in the correlated block $(3.0 \%)$ and in baseline $(1.37 \%)$ did not differ $[F<1]$.

The RT and the error analyses in Experiment 1 converged on two main patterns. First, the dimensional salience of spatial location was, by far, greater than that of color. Second, although the experiment underscored Garner interference from location to color and from color to location, the pattern of the Garner interference was asymmetric, in the sense that location intruded on color judgments to a larger degree than did color on location. This entails a pattern known as asymmetric integrality (Garner, 1974). The crucial theoretical implications of this pattern will be discussed later.

\section{Simon effects}

Only trials from the color judgment task were included in the analyses. Consistent with the bulk of research on the Simon effect (Hommel, 2011; Simon, 1976), congruent trials were defined as those trials in which the target's spatial location was on the same side as the required response (i.e., left-side location and left-hand response, right-side location and right-hand response), while incongruent trials were defined as those in which the side of the spatial location and the response location 
were on opposite sides. Simon congruency effect was present in all Garner blocks $\left[F(1,15)=30.58, p<0.000001, \eta_{p}^{2}=\right.$ $0.70]$, such that mean RTs in congruent conditions was $24 \mathrm{~ms}$ faster (423 ms) than mean RTs (447 ms) in incongruent conditions. The mean RTs and error rates per condition appear in Fig. 3. As can be noted, Simon effect was found under correlation $(410 \mathrm{~ms}$ in C- vs $347 \mathrm{~ms}$ in $\mathrm{C}+)[(t(15)=4.87$, $p<0.0005, d=0.97$ ], in filtering (498 $\mathrm{ms}$ in incongruent vs $483 \mathrm{~ms}$ in congruent trials) [ $(t(15)=1.92, p<0.05, d=0.15]$, and in baseline $(438 \mathrm{~ms}$ in congruent vs $430 \mathrm{~ms}$ in incongruent conditions) $[(t(15)=2.23, p<0.05, d=0.10]$. Note that the Simon effect in filtering and in baseline is a within-block effect; it is comparable to the effect documented in the bulk of studies, whereas the Simon effect under correlation is an across-blocks effect. Note that the target's location in the C+ block is Simon-congruent, whereas the target's location in the C- block is Simon-incongruent.

For error data, too, an overall Simon congruency effect obtained $\left[F(1,15)=15.31, p<0.005, \eta_{p}^{2}=0.50\right]$, such that larger error rates were found in incongruent trials $(6.9 \%)$ than in congruent conditions (3.9\%). Simon effect was recorded in the correlated blocks $(4.7 \%$ in $\mathrm{C}$ - vs $0.8 \%$ in $\mathrm{C}+$ ) $[(t(15)=2.68, p<0.005, d=0.88]$, in filtering $(9.2 \%$ in incongruent vs $5.3 \%$ in congruent trials) $[(t(15)=2.61, p<0.005$, $d=0.71]$, and in in baseline (6.9\% in incongruent vs $4.7 \%$ in congruent trials) $[(t(15)=2.95, p<0.005, d=0.52]$.

The possibility that the Simon and Garner effects reported here were affected by the mixing of location-relevant and location-irrelevant blocks (Proctor \& Lu, 1999) was tested and found to be unlikely. Participants who started with the color task were faster $(422 \mathrm{~ms})$ than those who started with the location task $(503 \mathrm{~ms})\left[F(1,14)=4.85, p=0.04, \eta_{p}^{2}=\right.$ $0.25]$, but most importantly, the effect of order did not interact with the Simon congruency factor $[F(1,14)=0.884, p=0.36$, $\left.\eta_{p}^{2}=0.05\right]$, nor with the type of Garner block $[F(2,28)=2.31$, $\left.p=0.11, \eta_{p}^{2}=0.14\right]$. These results strongly suggest that task order had no influence on the size of the Simon or Garner effects.

\section{Discussion}

Experiment 1 recorded several important outcomes. First, the experiment revealed an acute asymmetry in the discriminability of location and color. Spatial location was found to be a much more salient dimension to perception than color. Second, when judging color, participants could not filter out the irrelevant spatial location. Both the Simon and Garner effects - two separate measures of selective attentionattested to this conclusion. The Garner and Simon effects reflected the breakdown of selective attention to color due to intrusions from the irrelevant spatial location of the target (Garner, 1974). Further support for this conclusion comes from the finding of redundancy gains in judgments of color. The substantial Garner and Simon effects found here are commensurate with studies that argue for the precedence of location over nonspatial features (Simon \& Rudell, 1967; Tsal \& Lavie, 1993). Another valuable outcome is the finding of asymmetric Garner interference. Location interfered with color to a large extent, but color interfered with location judgments to a much lesser extent, as was evident by a smaller but significant Garner interference. The observed pattern of asymmetric Garner interferences is most commensurate with partial integrality (Garner, 1974; see also Algom \& Fitousi, 2016).

The finding that color and location produce asymmetric Garner interferences is compelling. Garner (1974) proposed a logical hierarchy account of asymmetric interferences. According to this account, if dimension A (e.g., color) exists then dimension B (e.g., location) also exists, but if dimension B (e.g., location) exists dimension A (e.g., color) may or may not exist. The pair of color and form is a good example for such an asymmetry because "color exists without a form, but a

\section{Simon Effects}

Experiment 1
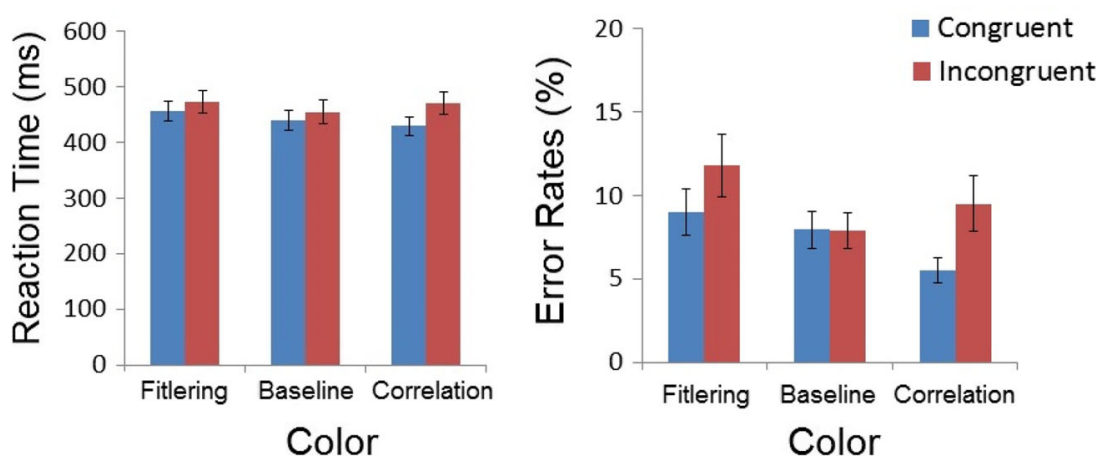

Fig. 3 Experiment 1, Simon effect for reaction time (left panel) and error rates (right panel) in conditions of Filtering, Baseline, and Correlated of the Garner design ( $m s$ milliseconds). Error bars are standard error of the mean 
form must have a color (Garner, 1974b, p. 137). Stroop dimensions provide another well documented example of an asymmetric interference (Melara \& Mounts, 1993; Melara \& O Brian, 1989; Sabri et al., 2002). Judgments of ink color are interfered by irrelevant variation on word to a larger extent than word classification is interfered by ink color. Interestingly, Garner's logical hierarchy idea aligns well with the idea that the color of a stimulus cannot be processed without first identifying the stimulus's location, a notion that is prevalent in both the attention and Simon effect literatures (Johnston \& Pashler, 1990; Nicoletti \& Umiltá 1989; Tsal \& Lavie, 1993).

However, several studies challenged the logical hierarchy perspective, showing that the degree of symmetry or asymmetry is determined by the powerful variable of relative dimensional salience or relative baseline discriminability (Algom et al., 1996; Algom \& Fitousi, 2016; Fitousi \& Algom, 2006; Fitousi \& Wenger, 2013; Garner \& Felfoldy, 1970; Melara \& Mounts, 1993; Pansky \& Algom, 1999, 2002). These studies have reached the conclusion that when the difficulty of discrimination with the two dimensions at baseline is mismatched, the more salient dimension (location) interferes with performance with the less salient dimension (color) more than vice versa. Mismatched dimensional salience has been shown to affect the Garner and Stroop outcome in a profound way (Fitousi \& Algom, 2006; Fitousi \& Wenger, 2013; Melara \& Mounts, 1993; Sabri et al., 2001). This mismatch may explain the asymmetric Garner interference observed here. In particular, the Simon effect and the Garner interference, which in combination provide a set of converging operations (Garner, Hake, \& Eriksen, 1956; Fitousi, 2013, 2015, 2016) on the influence of irrelevant location on feature-based attention, may not be generated by the logical hierarchy of location and color (Garner, 1974), but due to the advantageous discriminability of location over that of color (Algom \& Fitousi, 2016; Melara \& Algom, 2001; Melara \& Mounts, 1993).

\section{Experiment 2}

The goal of Experiment 2 has been to further test the influence of irrelevant location on performance using the Garner and Simon effects. According to the relative discriminability hypothesis (Fitousi \& Algom, 2006; Garner \& Felfoldy, 1970; Melara \& Algom, 2003; Melara \& Mounts, 1993) matched baseline discriminabilities may lead to perfect selective attention to the criterial dimension, and therefore to an elimination of the Garner and possibly the Simon effects. As a result, the color and location attributes should appear as separable dimensions. According to the logical hierarchy hypothesis (Garner, 1974), equating baseline discriminabilities should not alter the pattern of dimensional asymmetry. According to this approach, the dimensional interaction pattern is generated due to the privileged attentional status of location (Posner, 1980). In Experiment 2, an attempt has been made to judiciously render the dimension of spatial location as discriminable as the color dimension. This was done by presenting the target very close to the fixation point, a modification of the stimulus's psychophysical values that should, hopefully, reduce the discriminability of the location dimension relative to that of color.

\section{Methods}

\section{Participants}

Fourteen undergraduate students from Ariel University participated. They received course credit for their participation. All observer reported normal or corrected-to-normal vision. None of them participated in Experiment 1.

\section{Stimuli}

The stimuli were the same colored square shapes and fixation point used in Experiment 1. The only difference was that now the distance between the target (a colored square) and the fixation was shorter $\left(0.10^{\circ}\right.$ to the left or to the right of fixation, see Fig. 1 middle panel).

\section{Procedure and design}

The procedure and design were identical to those reported in Experiment 1.

\section{Results}

\section{Garner effects}

Trials with RTs shorter than $150 \mathrm{~ms}$ or RTs longer than $2,500 \mathrm{~ms}(1.1 \%)$ were excluded from analysis. Trials with incorrect responses $(0.6 \%)$ were also removed. Mean RTs and error rates in Experiment 2 are presented in Fig. 4. As in Experiment 1, spatial location ( $354 \mathrm{~ms}$ ) was more discriminable than color $(436 \mathrm{~ms})\left[F(1,13)=19.15, p<0.0001, \eta_{p}^{2}=\right.$ $0.54]$, in spite of the intent to equate the relative salience of the two dimensions. A further test of the baseline discriminabilities confirmed this conclusion, revealing better performance in the (averaged) location baseline $(346 \mathrm{~ms})$ than in the color baseline $(428 \mathrm{~ms})[t(13)=3.72, \mathrm{p}=0.002, d=1.44]$. Decreasing the distance between the two potential target's locations was not effective. But this, of course, also allows us to use the current results to test the reliability of Experiment 1 results, because in both experiments, location was more salient to perception than color. As for performance 


\section{Garner Effects}

Experiment 2

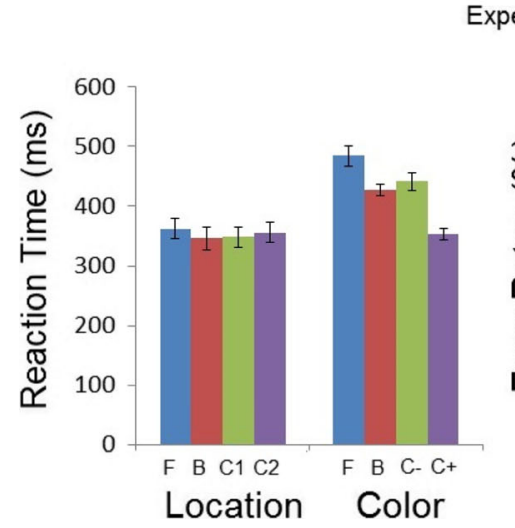

Fig. 4 Experiment 2, Garner effects in judgments of color and location for mean reaction time (left panel) and percentage of error rates (right panel). Location location task, Color color task, ms milliseconds, $F$

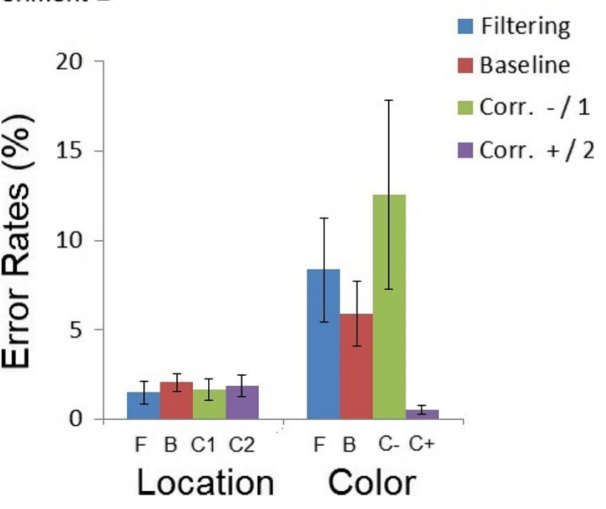

filtering, $B$ baseline, $C+$ positively correlated, $C$ - negatively correlated, $C 1$ correlated 1, $C 2$ correlated 2. Error bars are standard error of the mean

tasks, consider first judgments of color. The error rates in the two baselines were similar $(5.2 \%$ and $6.6 \%)[F<1]$. A numerical Garner interference was observed, as more errors were made in filtering $(8.35 \%)$ than in baseline $(5.9 \%)$, but the effect did not approach significance level $[F<1]$. The redundancy gain was large $(5.9 \%$ in baseline vs $0.55 \%$ in the positively correlated block), but only marginally significant $\left.\left[F(1,13)=3.90, p=0.054, \eta_{p}^{2}=0.07\right)\right]$. The redundancy loss (12.56\% in C- vs $5.9 \%$ in baseline) was on the verge of significance $\left.\left[F(1,13)=3.94, p=0.056, \eta_{p}^{2}=0.20\right)\right]$. As for judgments of spatial location, no Garner interference was obtained, because performance in filtering and baseline was comparable $(1.5 \%$ in filtering vs $2.08 \%$ in baseline) $[F(1$, $\left.13)=1.75, p=0.19, \eta_{p}^{2}=0.04\right]$. No redundancy effect obtained either, as error rate in the correlated blocks $(1.77 \%)$ did not differ from that in baseline $(5.9 \%)[F<1]$.

\section{Simon effects}

Analyses were restricted to trials from the color classification task. As can be seen in Fig. 5, Simon congruency effects were present in all Garner blocks $[F(1,13)=42.66$, $\left.p<0.00001, \eta_{p}^{2}=0.76\right]$, showing that on average, congruent trials (409 $\mathrm{ms}$ ) were responded to faster than incongruent trials (467 ms). Taking a closer look into the Garner blocks, it was revealed that Simon effects surfaced under correlation $(442 \mathrm{~ms}$ in $\mathrm{C}$ - vs $353 \mathrm{~ms}$ in $\mathrm{C}+)[(t(13)=6.88$, $p<0.00000001, d=1.91]$, in filtering (511 ms vs $462 \mathrm{~ms})$ $[(t(13)=3.42, p<0.005, d=0.71]$, and in baseline $(445 \mathrm{~ms}$ vs $412 \mathrm{~ms})[(t(13)=3.90, p<0.0005, d=0.80]$.

For error data, too, the overall Simon congruency effect was marginally significant $\left[F(1,13)=4.34 p=0.057, \eta_{p}^{2}=\right.$ 0.25 , with larger error rates made in incongruent trials (11.2. \%) than in incongruent conditions $(2.72 \%)$. Simon effect was recorded in the correlated blocks $(12.5 \%$ in C- vs $p=0.03, d=0.98]$. As for the performance patterns in the two 


\section{Simon Effects}

Experiment 2
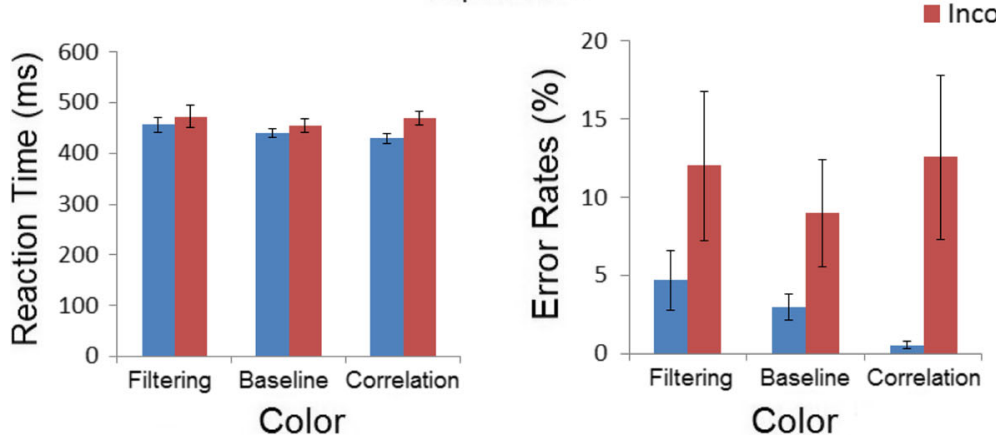

Fig. 5 Experiment 2, Simon effects in conditions of Filtering, Baseline, and Correlated of the Garner design (ms milliseconds). Error bars are standard error of the mean

$0.5 \%$ in $\mathrm{C}+)[(t(13)=2.36, p<0.05, d=0.85]$, in baseline $(9.0 \%$ vs $2.8 \%)[(t(13)=1.76, p=0.05, d=0.65]$, and in filtering $(12.0 \%$ vs $4.7 \%)[(t(13)=1.70, p=0.05, d=0.54]$.

\section{Discussion}

Experiment 2 provides a close replication of Experiment 1. It was initially planned as a genuine attempt at equating the baseline discriminabilities of color and location by reducing the spatial distance between the two possible targets locations. In spite of this manipulation, location remained more salient than color. However, the experiment does provide another source of validation support in the results of Experiment 1 . As in Experiment 1, both Garner and Simon effect were recorded. As in Experiment 1, the Garner interference was asymmetric. When judging color, participants could not ignore irrelevant variation on the target's location, and suffered both Garner interference and Simon effects. In contrast, when judging location, observers could perfectly ignore variation on color. It seems though that the asymmetric Garner interference pattern and the apparent difficulty in equating the baseline discriminabilities of color and location support the logical hierarchy account (Garner, 1974, see also Algom \& Fitousi, 2016). According to this proposal, the sole determinant of the processing of location and color is the logical implication that color cannot exist without location, but location can exist without color. However, at this stage, one cannot adjudicate between the logical hierarchy (Garner, 1974) and the relative discriminability (Fitousi \& Algom, 2006; Melara \& Mounts, 1994) hypotheses. What is needed is an effective manipulation that is capable of matching the baseline discriminabilities of color and location.

\section{Experiment 3}

In Experiment 3, additional measures were taken to equate the dimensional salience and the relative discriminabilities of color and location. When testing for the integralityseparability of dimensions (Garner, 1974), equating baseline discriminabilities is important in order to inform us on the dimensional relations between the attributes (Fitousi \& Algom, 2006; Garner \& Felfoldy, 1970; Melara \& Algom, 2003; Melara \& Mounts, 1993). To anticipate, this goal has been accomplished in Experiment 3.

\section{Methods}

\section{Participants}

A new sample of eighteen undergraduate students from Ariel University participated. They received course credit for their participation. All observers reported normal or corrected-tonormal vision.

\section{Stimuli}

The same stimuli from Experiment 1 and 2 were used. Two novel aspects of this experiment are: (a) removal of the fixation point, such that it was not used throughout the entire experimental trial, and (b) shortening of the distance between the target and the fixation point to $0.025^{\circ}$. Prior testing showed that this is the minimal distance with which observers can discriminate between two targets' locations with acceptable speed and accuracy.

\section{Procedure and design}

The procedure and design of Experiment 1 and 2 were subjected to several important modifications (see bottom panel of Fig. 1). The goal of these modifications ${ }^{1}$ has been to render the dimension of spatial location less salient to perception; this in

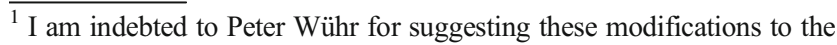
task.
} 
order to achieve matched discriminability of the two dimensions. Each trial started with blank that remained on the screen for $200 \mathrm{~ms}$. No fixation was presented throughout the experiment. The blank was followed by the target that could appear at one of two possible spatial locations on the screen. The distance between the target stimuli and the midline was shorted relative to Experiment 2. The removal of the fixation point and the shortening of the target distance from the middle should reduce the discriminability of the location dimension. Apart from these changes, all other aspects of the experiment, including trial sequence, number of blocks, Garner blocks (i.e., filtering, baseline, and correlated) and tasks (color and location judgments), were identical to those employed in Experiment 1 and 2.

\section{Results}

\section{Garner effects}

Trials with RTs shorter than $150 \mathrm{~ms}$ or RTs longer than $2,500 \mathrm{~ms}(0.6 \%)$ were excluded from analysis. Incorrect responses $(8 \%)$ were also removed. Mean RTs and error rates across the different conditions are presented in Fig. 6. The analysis showed that the dimensional salience and baseline discriminability of color and location were matched. First, classification latencies for location (444 ms) and color (459 ms) were comparable, as the difference between the two was far from significance $[F(1,17)=0.82, p=0.37$, $\left.\eta_{p}^{2}=0.04\right]$. A similar result obtained with respect to the baseline discriminabilities. Performance in the location baseline (431 ms) was comparable to that in the color baseline (464 ms) $[t(17)=1.51, p=0.13, d=0.33]$. This outcome entails that the experiment was successful in attaining its major goal-equating the salience of the two attributes. As for performance in the two tasks, consider first judgments of color. Performance in the two baseline blocks (457 ms vs $472 \mathrm{~ms}$ ) was comparable $[F<1]$, and the two blocks were merged into a single baseline. Most importantly, no Garner interference obtained in classification of color, such that the difference in processing speed between filtering $(477 \mathrm{~ms})$ and baseline (464 ms) was far from significance $[F(1,17)=0.97, p=0.33$, $\left.\eta_{p}^{2}=0.04\right]$. This absence of Garner interference in judgments of color entails that when attending to color, participants did not suffer interference from irrelevant trial-to-trial variation on the target's spatial location. The result is of major theoretical importance, because it refutes the "location-precedence hypothesis" (Posner, 1980), and supports the "relative discriminability hypothesis" (Garner \& Felfoldy, 1970).

Participants did incur redundancy loss, as performance in the negatively correlated block (477 ms) was $13 \mathrm{~ms}$ worse than performance in baseline $(464 \mathrm{~ms})[F(1,17)=4.99$, $\left.p=0.03, \eta_{p}^{2}=0.17\right]$. A redundancy gain has been recorded, with performance in the positively correlated block $\mathrm{C}+$ (415 ms) being $49 \mathrm{~ms}$ faster than that in baseline (464 ms) $\left[F(1,17)=6.66, p=0.01, \eta_{p}^{2}=0.21\right]$. Next consider judgments of location. Speed of processing under the two baselines conditions was on par (429 ms, $433 \mathrm{~ms})[F<1]$, and the data from the two blocks were pooled into a single baseline. Performance in filtering (452 ms) was slower than that in baseline (431 ms), amounting to a $21 \mathrm{~ms}$ Garner interference $\left[F(1,17)=5.55, p=0.03, \eta_{p}^{2}=0.18\right]$. The result indicates that when participants judged spatial location, they were interfered by irrelevant variation on color. Recall that in location classification, the sign of the correlated block is meaningless because the quality of S-R correspondence does not apply. The difference between the merged correlated block (451 ms) and baseline $(431 \mathrm{~ms})$ was not significant $[F(1,17)=1.36$, $\left.p=0.25, \eta_{p}^{2}=0.18\right]$, suggesting the absence of a redundancy effect in judgments of location.

\section{Garner Effects}

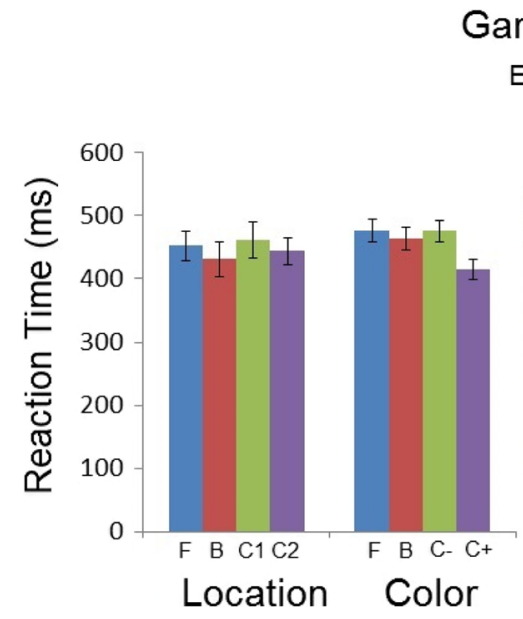

Fig. 6 Experiment 3, Garner effects in judgments of color and location for mean reaction time (left panel) and percentage of error rates (right panel). Location location task, Color color task, $m s$ milliseconds, $F$

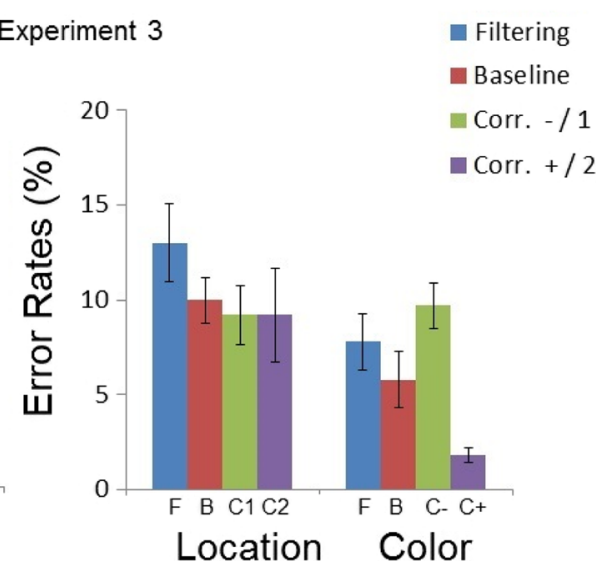

filtering, $B$ baseline, $C+$ positively correlated, $C$ - negatively correlated, $C 1$ correlated 1, $C 2$ correlated 2. Error bars are standard error of the mean 
The error data patterns were somewhat different than those found in the RT data. This difference was not due to a speedaccuracy tradeoff between the RT and error, because the correlation between reaction times and accuracy was close to null $[r=0.019, t(142)=0.22, p=0.82]$. Error rates in the color task $(6.5 \%)$ tended to be lower than error rates in the location task $(10.7 \%)\left[F(1,17)=8.83, p=0.05, \eta_{p}^{2}=0.34\right]$, a result that is commensurate with the increased difficulty of the location task. As for performance in the two tasks, consider first judgments of color. The two baselines (5.4\% vs $6.2 \%$ ) did not differ from each other $[F<1]$, and thus were merged into a single baseline. Garner interference was found in classification of color, such that performance in filtering produced more errors $(7.8 \%)$ than performance in baseline $(5.8 \%)\left[F(1,17)=5.47, p=0.03, \eta_{p}^{2}=\right.$ $0.17]$. This result shows that with respect to error data, location did interfere with color. Although error rates in the negatively correlated block $(9.7 \%)$ were larger than those in baseline $(5.8 \%)$, the difference was not significant $[F<1]$, suggesting the absence of a redundancy loss. Participants reaped redundancy gain due to positive correlation, showing more errors in baseline $(5.8 \%)$ than in the positively correlated block $(1.8 \%)$ $\left[F(1,17)=9.38, p=0.005, \eta_{p}^{2}=0.20\right]$. As for judgments of location, performance in the two baselines was on a par $(10 \%$ vs $10 \%)[F<1]$, and the two blocks were merged into a single baseline. Error rates in filtering (12.9\%) were comparable to those in baseline $(10 \%)[F<1]$, indicating the absence of Garner interference from color to location. Redundancy effects $(9.2 \%$ in correlation vs $10 \%$ in baseline) were not observed $[\mathrm{F}<1]$.

The disagreement between the RT and error data in Experiment 3, along with the absence of speed-accuracy tradeoff, is notable; especially given the close agreement found between the two dependent variables in Experiments 1 and 2. One possibility is that reaction times and error rates tap into two different processes (see Prinzmetal, McCool, \& Park, 2005). Another possibility is that the two variables capture a complex dynamics, one that can be better explained through the usage of more sophisticated information accumulation models, such as the diffusion model (Ratcliff, 1978). These models are capable of accounting for accuracy and reaction time simultaneously.

The Garner results, at least those from the RT data, show that when baseline discriminabilities of color and location are equated, location does not interfere with color. In Garnerian language, these results entail that color is separable from location, a conclusion that is commensurate with Zhang and Luck's (2009) argument that location is not activated automatically in feature-based attention.

\section{Simon effects}

For RT data, Simon congruency effects were observed in all types of Garner blocks $\left[F(1,17)=45.26, p<0.0005, \eta_{p}^{2}=\right.$ $0.72]$. Figure 7 presents mean RTs and error rates for congruent and incongruent conditions. As can be seen, the Simon effect surfaced under all Garner conditions. The Simon effect amounted to $17 \mathrm{~ms}$ in filtering $[t(17)=4.55, p<0.0005$, $d=0.20], 15 \mathrm{~ms}$ at baseline $[t(17)=2.15, p<0.05, d=0.16]$, and $41 \mathrm{~ms}$ under correlation $[(t(17)=5.11, p<0.00001$, $d=0.51]$. For error, too, an overall Simon effect was found $\left[F(1,17)=8.94, p<0.05, \eta_{p}^{2}=0.33\right]$. The Simon effect amounted to $2.8 \%$ error in filtering ( $11.7 \%$ vs $8.9 \%)$ $[t(17)=2.39, p<0.05, d=0.40], 4.0 \%$ in correlation $(9.5 \%$ vs $5.5 \%)[t(17)=2.82, p<0.05, d=0.71]$, but was absent in baseline $(7.9 \%$ vs $7.9 \%)[t<1]$.

\section{Discussion}

The results of Experiment 3 are novel and informative in various respects. First, they show that the relative discriminability of location and color can be matched. Under matched discriminability, Garner interference from location to color is virtually eliminated and the color dimension appears as separable from

\section{Simon Effects}

Experiment 3
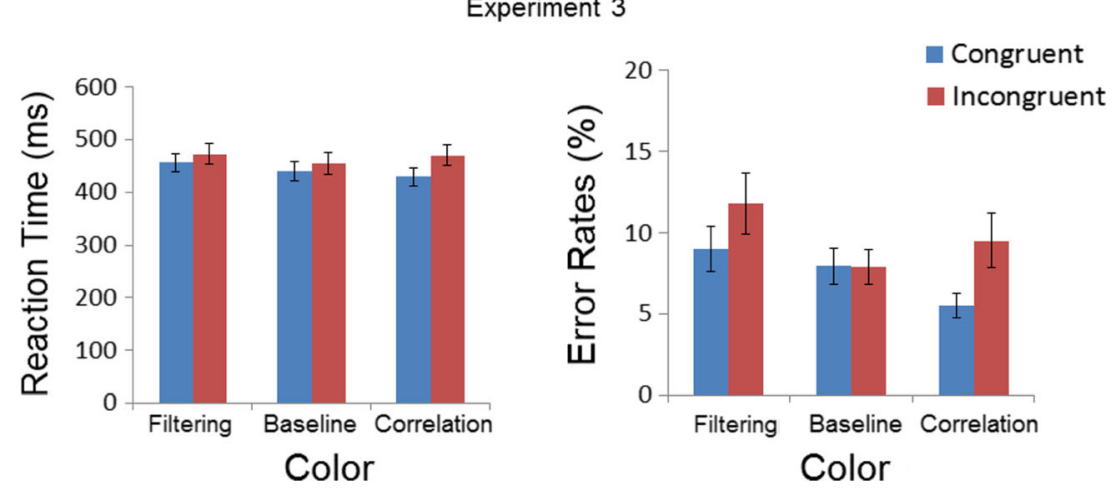

Fig. 7 Experiment 3, Simon effects in conditions of Filtering, Baseline, and Correlated of the Garner design (ms milliseconds). Error bars are standard error of the mean 
the location dimension. In contrast, the Simon effects are still recorded. This set of results provides an intriguing dissociation between the Garner interference and the Simon effect. On the one hand, the Garner results suggest that location did not intrude on color judgment; on the other hand, the Simon effects entail that location did interfere with color. This is a puzzling pattern that certainly requires a novel explanation. Note that when the Garner interference is found, it entails that participants noted the variation on the irrelevant dimension; and when the Simon effect is found it entails that participants noticed the value of the irrelevant dimension. According to this logic, Simon effects cannot be found without Garner interference, because one first has to notice variation before noticing the value of variation. This neat logic has been invoked to account for the finding that the Stroop effects are often not found without Garner effects (Clark \& Brownell, 1976; Melara \& Algom, 2003, Pomerantz, 1983, and Pomerantz, Pristach, \& Carson, 1989), although this logic has not always been supported (Eitan, Schupak, Gotler, \& Marks, 2014; Martino \& Marks, 2000; Patching \& Quinlan, 2002; Van Leeuwen \& Bakker 1995). As for the Garner and Simon effects recorded here, this logic might not apply to them. Here I found Simon effects without Garner interference, an outcome with profound importance for understanding the influence of irrelevant spatial location on performance.

With respect to the Garner interference results, they refute the hierarchical logic approach (Garner, 1974), according to which an asymmetric pattern of Garner interferences reflects a logical implication by which one dimension (location) implies the other (color), but not vice versa. Experiment 3 demonstrated that the precedence of location over color is not inherent or generic, but can be altered through a slight change in the relative dimensional salience of the two attributes. The results are consistent with the relative discriminability approach (Algom et al., 1996; Fitousi \& Algom, 2006; Garner \& Felfoldy, 1970; Melara \& Algom, 2003; Melara \& Mounts, 1993) that ascribes the Garner interference to the degree of mismatch in baseline discriminability of the two dimensions. According to this approach, relative discriminability dictates the manner by which selective attention succeeds or fails. When baseline discriminability is matched, selective attention to the relevant dimension can be perfect, and participants do not suffer intrusions from trial-to-trial variations on the irrelevant dimension. The Garner results are commensurate with Zhang and Luck's (2009) claims concerning the independence of spatial and non-spatial attributes. However, neither of these approaches can explain the emergence of the Simon effect in tandem with the elimination of the Garner interference.

A recent study by Melara et al. (2008) has combined a Garner and Simon effect methodology with an electrophysiological analysis of auditory classification. Although this study examined the auditory Simon effect and not the visual Simon effect, a lot can be learned from it.
Participants in the Melara et al. (2008) study were asked to classify the timber of a tone coming from either the left of or right ear. Melara et al. (2008) recorded both Garner and Simon effects. The electrophysiological measures revealed that an ERP signature of the Simon effect showed up approximately $250 \mathrm{~ms}$ after stimulus onset in the N2 component, whereas an ERP signature of the Garner interference was present $100 \mathrm{~ms}$ after stimulus onset in the N1 component and reflected by greater negativity in the filtering condition than in the baseline condition. These authors also found a strong correlation between the peak latency of the P3 decisional component and RTs to the Simon congruent and incongruent stimuli. Both the behavioral and the electrophysiological results adduced by Melara et al., (2008) are important and relevant for the current study. However, Melara et al. s interpretation of the relations between the Garner and Simon effects is rendered untenable by the present results. In particular, Melara et al. s argument that: "the Simon effect is prompted by an early failure of attention to the relevant dimension from irrelevant trial-totrial change in stimulus location" (p.154) is not supported by the current data. Note that according to Melara et al. $\mathrm{s}$ account, the Simon effect depends on the Garner interference. That is, attention to the congruency or incongruency of the stimulus location was possible only after failure of selective attention to the irrelevant variation on location. In other words, noticing the value of the location dimension required noticing variation on this dimension in the first place. A similar explanation has been invoked to account for the finding that Stroop effects are not observed without Garner interference (Melara \& Algom, 2003; Sabri et al., 2001). However, several findings in the present study militate against Melara et al. (2008) conclusions concerning the structural dependency of the Simon effect on the Garner interference.

First, it has been shown here that when the dimensional discriminability of the location dimension is matched to that of color, the Garner interference from location to the relevant attribute is completely abolished, whereas the Simon effect is still obtained. This means that, in contrast to Melara et al. (2008) conjecture, participants suffered from the inadvertent influence of location in the Simon effect, while being capable of ignoring the trial-to-trial irrelevant variation on location at the same time. It should be noted that Melara et al. (2008) have not equated the dimensional discriminability or dimensional salience of their auditory attributes, nor have they measured performance in a location classification task. This makes it difficult to know whether the Garner and Simon effects with their auditory dimensions could be dissociated. Second, Melara et al. (2008) have argued that "the Simon effect was robust in the filtering task, but only weakly present in the baseline task, indicating a further link between selective attention failure (to sound) and S-R correspondence" (p.154). According to their way of reckoning, baseline location does not vary from trial-to-trial, and therefore selective attention to 
location cannot fail, leading to very small to nonexistent Simon effects in baseline. However, the results of the current study refute this idea, showing that a comparable Simon effect can be recorded in filtering and baseline conditions.

\section{A triple-route model of color and location processing}

A common assumption shared by researchers in the areas of visual attention (Johnston \& Pashler, 1990; Tsal \& Lavie, 1993 ) and the Simon task (De Jong et al., 1993; Simon \& Small, 1969) postulates that the processing of featural attributes of a stimulus is contingent on processing of its spatial location (but see Ansorge \& Wühr, 2009; Valle-Inclán \& Redondo 1998 ; Wühr \& Biebl, 2011). The assumption is embedded in each of the following popular notions: (1) the logical hierarchy model (Garner, 1974; Treisman \& Gelade, 1980; Posner, 1980), according to which color implicates spatial location but location does not implicate color, (2) the attention hypothesis, according to which an orienting reflex is executed toward a target that "pops out" in a certain location (Posner, 1980; Simon \& Small, 1969; Nicoletti \& Umiltá 1989, 1994), and (3) dual route models and the relative speed of processing account (Hommel, 1993b), according to which location is processed more rapidly than other non-spatial attributes. The Garner and Simon effect results adduced in Experiments 1-3 cannot be accommodated by any of these accounts. First, the hierarchical logic (Garner 1974) and the attention (Nicoletti \& Umiltá 1989, 1994) approaches are untenable because they cannot explain our ability to match the two dimensions' relative discriminability, as well as the elimination of the Garner interference. Second, the relative speed of processing account (De Jong et al., 1994) cannot accommodate the finding that the Simon effect was present even when the baseline speeds of location and color were matched (i.e., via dimensional discriminability), nor can it explain the finding that color did interfere, albeit to a small degree, with location judgments in Experiments 1 and 3.

Here I entertain a novel hypothesis that aims at accounting for the apparently conflicting facets of the current data. The hypothesis postulates a triple-route/code model that consists of - in addition to the featural route/code (i.e., color) - two spatial location routes/codes that can interact with the color route. The first route/code, gauged by the Garner interference, is voluntary, and amenable to influences of attentional control via dimensional salience. The second route/code is automatic, involuntary, and unaffected by manipulation of salience or attention. The model depicted in Fig. 8 instantiates the two routes/codes within a structural model in the spirit of the classic attentional selection models (Broadbent, 1958; Deutsch \& Deutsch, 1963), and dual-route models of the Simon effect (De Jong et al., 1994). The first S (Simon) location route is subjected to a stimulus selection stage, and then to a response selection stage, governed by a late-selection process (Deutsch \& Deutsch, 1963); whereas the second G (Garner) location route/code halts at the stimulus selection stage, and is subjected to early selection. The model gains further support from the electrophysiological results of Melara et al. (2008), which showed an early ERP signature for the Garner interference, accompanied by a subsequent ERP signature of the Simon effect, and then a decisional component that is correlated with the Simon effect. Additional support to the independence of the $S$ and $G$ routes in the current model is presented next. The support comes from various analyses indicating that the Simon effect and Garner interference are independent indices of spatial location activation.

\section{No correlations between Garner interferences and Simon effects}

One approach to testing whether the Garner and the Simon measures are two independent indices of spatial activation is by looking at their correlations (see Pomerantz, Pristach, \& Carson, 1989, for a similar strategy in the case of the Garner and Stroop effects). Individual scores of Garner interference and Simon effect in filtering were computed separately for each participant in each experiment. The Pearson correlation coefficient did not differ from zero in all three experiments: Experiment $1,\left(r_{p}=-0.17\right)[t<1]$, in Experiment $2,\left(r_{p}=0.23\right)$ $[t<1]$, although in Experiment 3 the correlation was larger $\left(r_{p}=0.41, t(17)=1.83, p=0.08\right]$. Taken together, these correlational results might suggest that the Garner interference and the Simon effect are tapping into two independent mechanisms of location activation.

Small and non-significant correlations have also been found between redundancy losses and the Simon effect: in Experiment $1,\left[r_{p}=-0.28, t(14)=-1.11, p=0.28\right]$, in

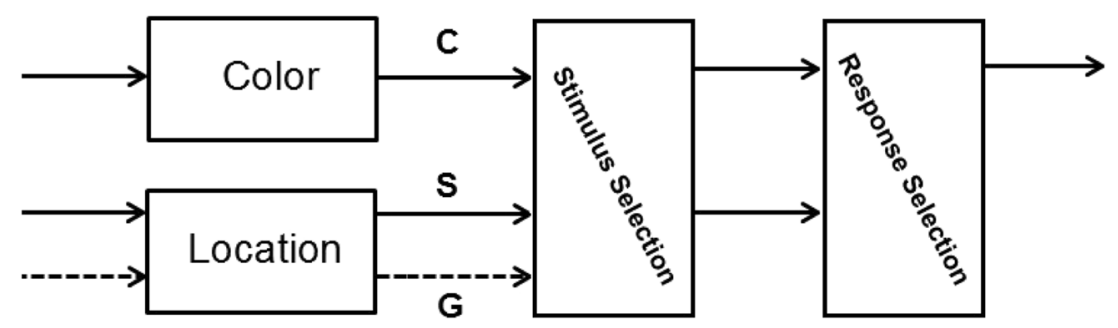

Fig. 8 A structural model of the processing of color and spatial location. $C$ color route, $S$ a late-stage process of location selection gauged by the Simon effect, $G$ an early-stage process probed by Garner interference 
Experiment 2, $r_{p}=0.42[t(12)=1.60, p=0.13]$, and in Experiment $3 r_{p}=-0.20[t<1]$. Similarly, redundancy gains were not correlated with the Simon effect: in Experiment 1 $\left[r_{p}=-0.29, t(14)=-1.17, p=0.26\right]$, in Experiment $2\left[r_{p}=-\right.$ $0.41, t<1]$, and in Experiment $3\left[r_{p}=-0.30, t<1\right]$. It is likely that the Garner measures and the traditional Simon effect (in filtering) are separate indicators of spatial activation. However, a correlational approach, it should be noted, is limited. This is because a finding of zero correlation might not imply independence (Fitousi, 2013; Garner \& Morton, 1969), and because the Pearson correlation is ineffective in detecting non-linear correlations.

\section{Diverging delta plots for Garner interferences and Simon effects}

A distributional analysis on the entire RTs is another means to investigating the differences between the Simon and Garner effects. This approach goes well beyond the mean RTs. In particular, delta plots (De Jong et al., 1994) depict the size of the effect (e.g., MRT incongruent-MRT congruent) as a function of time. Delta plots do not capture all of the information in the underlying RT distribution, but they do bring into light the differences between distributions. Delta plots can show a positive, negative, or zero slope (Pratte, Rouder, Morey, \& Feng, 2010), which have correspondence with various processing theories. For example, all positive and increasing delta plots, for example, are compatible with either drift rate or bound changes in the diffusion model (Ratcliff, 1978), or with the insertion of stages in processes (Ashby \& Townsend, 1980). It has been shown that delta-plot analyses of the Simon effect often reveal negative slopes for horizontal targets (De Jong et al., 1994; Pratte et al., 2010), and zero slopes for vertically oriented targets (Pratte et al., 2010). For comparison, delta plots for the Stroop effect often reveal a positive and increasing pattern (Pratte et al., 2010). Zhang and Kornblum (1997) argued that the slope of the delta plot may also result from manipulations on the variability parameters of the underlying distributions. However, here I use the delta plots only to show that Simon and Garner effects produce diverging delta plots. It is not my goal to account for the processes that produced these delta plots (see also Ridderinkhof, 2002a).

Delta-plots were derived for each of the Simon and Garner measures by, first computing the size of the effect in each of the 10-90 percentiles, and then plotting these values against their corresponding mean RT values (see for Pratte et al., 2010). The derived delta plots are presented in Fig. 9. To confirm the impressions evoked by visual inspection, linear regression coefficients for each delta-plot were derived. Most importantly, diverging patterns were found for the Simon (in filtering) and Garner interference effects. In Experiment 1, the regular Simon effect in filtering and the Garner interference diverged, such that the former revealed a negative slope [beta $=-6.51, R^{2}=0.88, F(1,7)=55.81, p<0.0005$ ] (see also De Jong et al., 1991; Pratt et al.,2009; Ridderinkhof, $2002 \mathrm{a}, \mathrm{b})$, whereas the latter exhibited a positive slope $\left[\right.$ beta $\left.=8.54, R^{2}=0.84, F(1,7)=39.1, p<0.0005\right]$. Interestingly, the Simon effect in baseline showed a zero slope [beta $\left.=1.31, R^{2}=0.005, F(1,7)=0.03, p=0.8\right]$, whereas the Simon effect under correlation exhibited a positive slope [beta $\left.=3.37, R^{2}=0.93, F(1,7)=106.5, p<0.00001\right]$. This suggests that the three types of Simon effects might tap into separate processes. The redundancy gain effect showed a positive slope $\left[\right.$ beta $=3.53, R^{2}=0.95, F(1,7)=175.1$, $p<0.000001]$, as did the redundancy loss effect [beta $\left.=12.41, R^{2}=0.89, F(1,7)=67.69, p<0.000001\right]$.

In Experiment 2, the Simon effect in filtering and the Garner interference also exhibited an opposite pattern, with the former having a zero slope [beta $=9.35$, $\left.R^{2}=0.05, F<1\right]$, and the latter generating a positive slope $\left[\right.$ beta $=3.95, R^{2}=0.88, F(1,7)=54.04$, $p<0.0005]$. As in Experiment 1, the Simon effect in baseline had a zero slope [beta $=8.54, R^{2}=0.26$, $F(1,7)=2.58, p=0.15]$, whereas the Simon effect under correlation exhibited a positive slope $\left[\right.$ beta $\left.=2.41, R^{2}=0.96, F(1,7)=206.2, p<0.000\right]$. As in Experiment 1, the delta plot of the redundancy gain effect showed a positive slope $\left[\right.$ beta $=4.28, R^{2}=0.93$, $F(1,7)=117.3, p<0.00001]$, but the redundancy loss effect showed a negative slope $\left[\right.$ beta $=-8.15, R^{2}=0.42$, $F(1,7)=6.01, p=0.03]$.

Experiment 3 provided another opportunity to test the independence hypothesis. Because the data point of the 90th percentile deviated from the other points in the delta plots for both the Garner and the Simon effect, it was removed from analysis (see for Ridderinkhof, 2002a, b). For the Simon effect the delta plot showed a positive slope $\left[\right.$ beta $=10.24, R^{2}=0.97, F(1,7)=247.4$, $p<0.000001]$. For the Garner effect, the slope was zero $\left[\right.$ beta $\left.=7.99, R^{2}=0.24, F(1,7)=1.9, p=0.21\right]$, indicating that the two effects diverged with respect to their delta plot slopes. The Simon effect in baseline had a positive slope [ beta $\left.=7.9, R^{2}=0.93, F(1,7)=71.72, p<0.005\right]$, as did the Simon effect under correlation $\left[\right.$ beta $=5.02, R^{2}=0.89$, $F(1,7)=59.93, p<0.0001]$, and the redundancy gain effect $\left[\right.$ beta $\left.=12.83, R^{2}=0.88, F(1,7)=60.51, p<0.00005\right]$. However, the redundancy loss had a negative slope [beta $\left.=-13.60, R^{2}=0.77, F(1,7)=27.24, p<0.005\right]$.

The correlational analyses and the delta-plot results corroborated the idea that the Garner interferences and the Simon effects are unrelated to each other. It is highly likely that the two probe separate processes/codes pertinent to the activation of irrelevant location. Taken collectively, the results from the current study provide substantial support in the triple-route model proposed here. 


\section{Simon Effect}

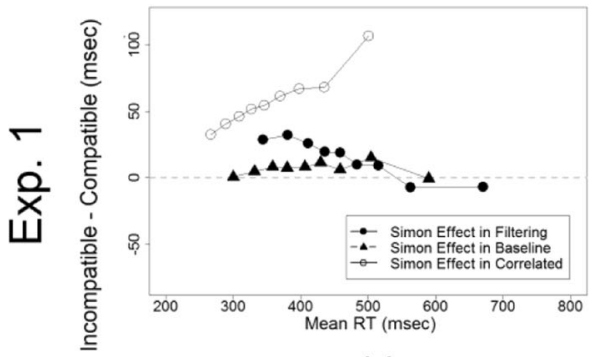

(a)

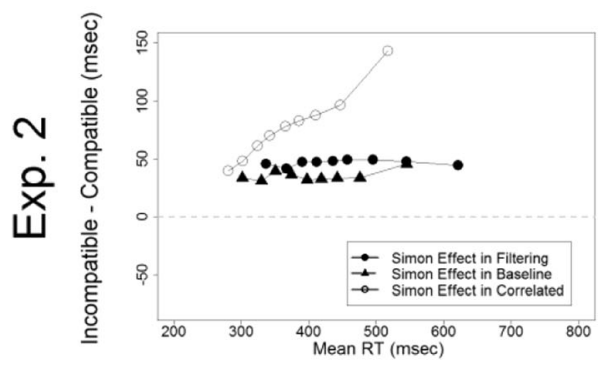

(d)

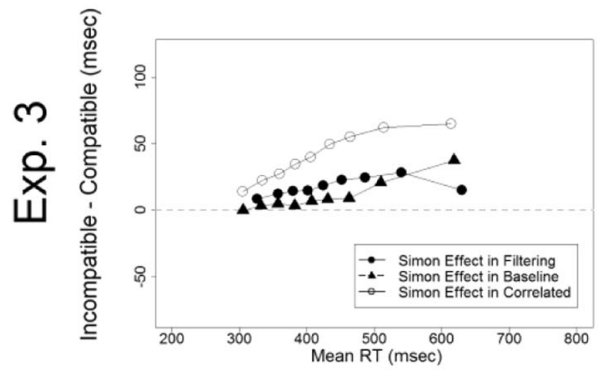

(g)
Garner Interference

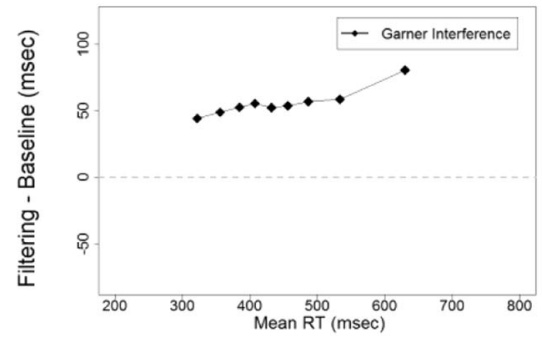

(b)

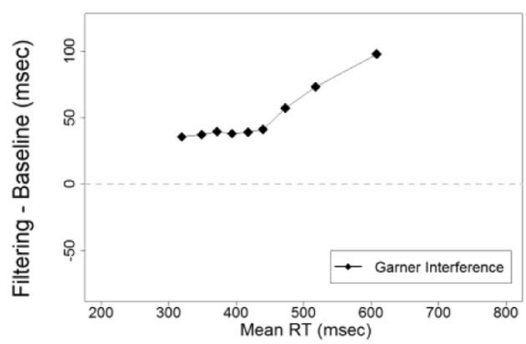

(e)

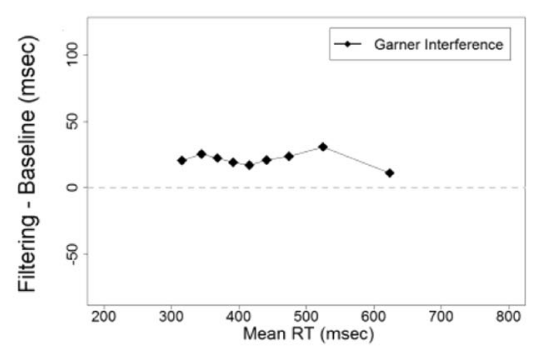

(h)
Redundancy

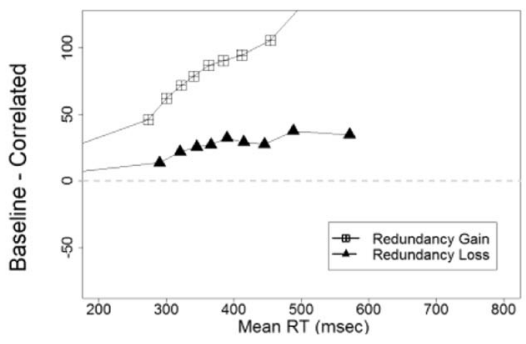

(c)

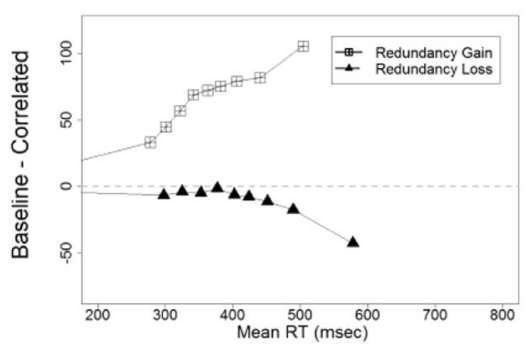

(f)

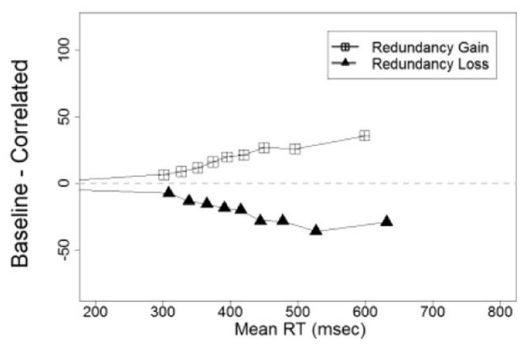

(i)
Fig. 9 Delta plots for the Simon and Garner effects in Experiments 1-3. a Simon effects in Experiment 1, b Garner interference in Experiment 1, c redundancy gains and losses in Experiment 1, d Simon effects in Experiment 2, e Garner interference in Experiment 2, f redundancy

\section{General discussion}

Three experiments elucidated the dimensional relations ensuing between spatial location and color. In each experiment, participants engaged in two tasks. In one task, they classified the color of a target, while ignoring variations on its spatial location. In a second task, participants classified the spatial location of the target, while ignoring variation on its color. The results showed that when the discriminability of location and color were unmatched, such that location was a more salient dimension for perception, asymmetric Garner effects were obtained. The more discriminable dimension (location) intruded on the less discriminable dimension (color) to a greater extent than vice versa. In addition, Simon effects were recorded in color judgments, providing a converging indication for inadvertent activation of location. However, when relative discriminability was matched, such that color and location gains and losses in Experiment 2, g Simon effects in Experiment 3, h Garner Interference in Experiment 3, i redundancy gains and losses in Experiment 3

were rendered, by intention, equally salient for perception, the Garner interference from location to color was virtually eliminated. Notably, the Simon effect still emerged in full force. The resurfacing of a Simon effect in the absence of Garner interference from location to color is an important result. It may reveal two possible routes by which irrelevant location affects performance. In all experiments, participants reaped appreciable redundancy gains due to positive correlation between color and location. However, rarely have they suffered from redundancy losses due to negative correlation. In conditions in which the dimensions were correlated, either positively or negatively, a Simon effect, defined as a difference between negatively and positively correlated dimensions, was present throughout, irrespective of the match or mismatch in discriminability. Simon effects also emerged in filtering and baseline conditions, mimicking the traditional Simon effects found in the literature (Simon \& Rudell, 1967; 
Wühr, 2006). The results of the present study bear important implications for the theories of dimensional interaction, selective attention, and the Simon effect. These are discussed next.

\section{Are intrusions from location to color mandatory?}

A single interpretation accounts best for the patterns documented in this study. The interpretation relies on a tripleroute model presented in the previous sections (see Fig. 8). The model makes a fundamental distinction between two types of location activation routes/processes/codes. One route is perceptual, voluntary, and early-selection-based - and is captured by the Garner interference; the second route is response-related, involuntary, and late-selection-based - and is captured by the Simon effect. The distinction made here between these two routes/codes is akin to the firmly established distinction between action and perception routes (Milner \& Goodale, 1995). It is also in agreement with proposals (Toth, Levine, Stuss, Oh, Winocur, \& Meiran, 1995) that relate the Simon effect to an action-based route. Various sources of evidence support the triple-route model. The first is provided by the results of Experiment 3, which demonstrated a clear dissociation between the Garner and the Simon effect in the reaction time data (i.e., Simon effect but no Garner interference).

A second source of support comes from the correlational analyses and the delta-plot investigations performed on the entire RT distribution, which revealed a convincing dissociation between the Garner interference and Simon effect. A third source of support is provided by Melara et al. s (2008) electrophysiological findings of two ERP signatures: one occurring at an early stage and reflecting the Garner interference; the second, showing up at a late stage, and reflecting the Simon effect. A fourth line of support comes from the response-discrimination account of the Simon effect suggested by Ansorge and Wühr (2004, see also Wühr \& Ansorge, 2007). According to this theory, the Simon effect shows up only when stimulus locations correspond to the top-down selected spatial codes used to discriminate between alternative responses. This proposal entails that the Simon effect is a semantic phenomenon that requires a responserelated adjustment, unlike the Garner effect, which, by definition, does not involve semantic adaptation, and therefore can be manipulated via changes in perceptual salience. A fifth source of support in the triple-route model comes from a recent study by Fitousi et al. (2009), showing dissociation between the Garner interference and the SNARC effect (Dehaene, Bossini, \& Giraux, 1993) - a possibly close relative of the Simon effect (Gevers, Caessens, \& Fias, 2005). Fitousi et al. (2009) demonstrated that a SNARC effect can be obtained without Garner interference.

To better understand how the triple-route model proposed here explains the results, consider first performance under the orthogonal context (filtering) in condition of unmatched discriminability. In this condition, participants could not filter out trial-to-trial variation on location, simply because location was more discriminable than the criterial dimension of color (Garner \& Felfoldy, 1970; Melara \& Algom, 2003). Under this condition, participants supposedly activated the $G$ (Garner) route/code. However, in the matched discriminability orthogonal context, participants could ignore the G (Garner) location code, simply because their selective attention was not drawn to location, which was equally salient to perception as the criterial dimension of color (Algom et al., 1996; Fitousi \& Algom, 2006; Melara \& Mounts, 1993). In both matched and mismatched discriminability conditions, participants activated the $\mathrm{S}$ (Simon) location code which consequently produced the Simon effect.

Consider next performance under the context of correlation. In that case, participants activated the $\mathrm{S}$ (Simon) location code/route, probably due to the gain they incurred from the predictive value of the irrelevant dimension (Algom et al. 1996; Fitousi \& Wenger, 2013; Melara \& Mounts, 1993). According to Maddox (1992), a strategic failure of selective attention to the irrelevant dimension under correlation captures a decisional rather than perceptual component. Beyond the well documented fact that the Simon effect is amenable to strategic influences via the proportion of congruent trials (Hommel, Proctor, \& Vu, 2004; Melara et al., 2008; Stürmer, Leuthold, Soetens, Schroter, \& Sommer, 2002), there are additional reasons to believe that the correlation condition reflects the activation of the $\mathrm{S}$ (Simon) location code. Two findings from the present study are particularly telling.

The first finding is that redundancy gains were more prominent than redundancy losses, meaning that observers attended to the irrelevant location only when it was Simon congruent (i.e., response location corresponded to the target's location), but not when it was Simon incongruent. The second finding is that participants were faster in the positively correlated blocks than in the negatively correlated blocks, producing an across-block Simon effect. These two facts entail that under correlation context, observers have probably activated the $\mathrm{S}$ (Simon) location code. But when the discriminability of location has been better than that of color, observers attended to location, activating both the $\mathrm{G}$ (Garner) and the S (Simon) location routes/codes. This resulted in Garner interference, redundancy gains (but still no losses), and Simon effects. The possibility that a decisional component governs the correlation and Simon effects (redundancy gains, Simon effect in filtering, and Simon effect in correlated task) is also in agreement with Melara et al. s (2008) finding of a strong correlation between the Simon effect with a decisional P1 component. Future work may be able to further test this account. 


\section{Independence of feature-based and space-based attention}

One of the triggers for conducting the current investigation has been Zhang and Luck's (2009) remarkable finding that feature-based attention operates independently of spacebased attention. The current results are consistent with Zhang and Luck's (2009) conclusions that space-base and feature-base attention can operate independently. They challenge the dominant view that the processing of nonspatial attributes is contingent on the processing of spatial location (Eimer, 1995; Lavie \& Tsal, 1993; Posner, 1980; Treisman \& Gelade, 1980). The present study shows that, in agreement with the study of Zhang and Luck (2009), the two types of attention can indeed operate independently of each other. Color and location appeared, under matched discriminability as separable dimensions. When the two dimensions were not matched on discriminability, as has probably been the case in the majority of studies in the attention literature, color and location appeared as integral dimensions.

However, the picture might be more convoluted than this. Looked at from the perspective of the Simon effect, the dimensional independence of color and location did not hold. One possible reason is that the Simon effect might be produced via a different location code than the one operating in feature-based attention (i.e., the $\mathrm{S}$ route in the triple-route model). Zhang and Luck's (2009) conjecture does not entertain the possibility of a late, decisional location code. It should be acknowledged that the Simon effect itself is malleable by various experimental manipulations, such as an increase in the task's cognitive load (Wühr, \& Biebl, 2011), presentation of the S-R mapping rules after the appearance of the imperative stimulus (Valle-Inclán \& Redondo 1998), or increase in the difficulty of the task (Hommel, 1993a; Roswarski \& Proctor, 1996). It also should be stressed that independence is not a unitary concept (Garner \& Morton, 1969), and the concept consists of various definitions, measures, and types (Fitousi, 2013, 2014, 2015; Garner \& Morton, 1969).

Finally, a word is in order regarding the small but significant interference from color to location found in Experiments 1 and 3. The Garner paradigm provides an opportunity for a direct competition between two dimensions. The small interference observed from color to location is therefore consistent with Zhang and Luck s (2009) argument that with increased competition "color-based attention may affect the flow of feedforward sensory information within $100 \mathrm{~ms}$ of stimulus onset, even if the stimuli were presented at an unattended location," (p.25).

\section{Spatial location as a stimulus dimension}

This is the first study that gauges the visual Simon effect and the Garner effect within a single experimental design. Such a combined design allows the researcher a broader scope on the influence of irrelevant location on performance. The Garner paradigm has been often harnessed to study the dimensional relations between attributes such as color, orientation, hue, brightness, as well as many other perceptual and auditory dimensions (Algom \& Fitousi, 2016; Algom et al., 1996; Fitousi \& Wenger, 2013; Fitousi, 2015; Garner \& Felfoldy, 1970; Melara \& Marks, 1990). However, spatial location in the Garner tradition has not been considered as a stimulus dimension. In particular, the stimulus in the Garner paradigm is often restricted to a single location in space, and the participant's task is that of dissecting the stimulus into its constituent dimensions (but see Garner \& Felfoldy, 1970, Experiment 3). This might be the reason that spatial location has not been studied as a dimension in the Garner paradigm. The closest efforts at doing so appear at the study by Melara et al. (2008), and a study by Shalev and Algom (2000) that examined the influence of spatial cuing (Posner, 1980) on the dimensional analysis of Stroop stimuli (Stroop, 1935) in the Garner task. Shalev and Algom (2000) found that the two types of attentionPosner's spatial cuing effect and the Garner's dimensional interference - are independent of each other. Posner and Garner effects were found, but no interaction between the two ensued. Using a similar paradigm, Fan, McCandliss, Sommer, Raz, and Posner (2002) have adduced evidence that supported the independence of three attention networks in the brain: alerting, orienting, and executive attention. The present study is commensurate with Fan et al. s claim for the independence of attentional systems, and with Hommel's $(2004,2011)$ conjecture that various types of stimulus and response codes may conflate to produce many of the experimental phenomena we observe. Future work should seek to further reveal the mechanisms that produce the Garner and Simon effects.

Acknowledgments I would like to thank Dr. Peter Wühr for his many insightful comments, suggestions, and ideas that have helped improve this work. I would also like to thank Abir-Zion Shasha and Hadar Saadon for helping with the data collection. Correspondence regarding this manuscript should be mailed to danielfi@ariel.ac.il.

\section{Compliance with ethical standards}

Funding This study was not funded by any grant.

Conflict of interest Daniel Fitousi declares that he has no conflict of interest.

Ethical approval All procedures performed in studies involving human participants were in accordance with the ethical standards of the institutional and/or national research committee and with the 1964 Helsinki declaration and its later amendments or comparable ethical standards. 
Informed consent Informed consent was obtained from all individual participants included in the study.

\section{References}

Algom, D., Dekel, A., \& Pansky, A. (1996). The perception of number from the separability of the stimulus: The Stroop effect revisited. Memory \& Cognition, 50, 557-572.

Algom, D., \& Fitousi, D. (2016). Half a century of research on Garner interference and the separability-integrality distinction. Psychological Bulletin. In press.

Anllo-Vento, L., \& Hillyard, S. A. (1996). Selective attention to the color and direction of moving stimuli: Eelectrophysiological correlates of hierarchical feature selection. Perception \& Psychophysics, 58(2), 191-206.

Ansorge, U., \& Wühr, P. (2004). A response-discrimination account of the Simon effect. Journal of Experimental Psychology: Human Perception and Performance, 30(2), 365-377.

Ansorge, U., \& Wühr, P. (2009). Transfer of response codes from choiceresponse to go/no-go tasks. The Quarterly Journal of Experimental Psychology, 62(6), 1216-1235.

Ashby, F. G., \& Townsend, J. T. (1980). Decomposing the reaction time distribution: Pure insertion and selective influence revisited. Journal of Mathematical Psychology, 21(2), 93-123.

Broadbent, D. E. (1958). Perception and communication. New York: Oxford University Press.

Burle, B., van den Wildenberg, W., \& Ridderinkhof, K. R. (2005). Dynamics of facilitation and interference in cue-priming and Simon tasks. European Journal of Cognitive Psychology, 17(5), 619-641.

Clark, H. H., \& Brownell, H. H. (1976). Position, direction, and their perceptual integrality. Perception \& Psychophysics, 19(4), 328-334.

De Jong, R., Liang, C. C., \& Lauber, E. (1994). Conditional and unconditional automaticity: A dual-process model of effects of spatial stimulus-response correspondence. Journal of Experimental Psychology: Human Perception and Performance, 20(4), 731-750.

Dehaene, S., Bossini, S., \& Giraux, P. (1993). The mental representation of parity and number magnitude. Journal of Experimental Psychology: General, 122(3), 371.

Deutsch, J. A., \& Deutsch, D. (1963). Attention: Some theoretical considerations. Psychological Review, 70, 80-90.

Eimer, M. (1995). Event-related potential correlates of transient attention shifts to color and location. Biological Psychology, 41(2), 167-182.

Eitan, Z., Schupak, A., Gotler, A., \& Marks, L. E. (2014). Lower pitch is larger, yet falling pitches shrink: Interaction of pitch change and size change in speeded discrimination. Experimental Psychology, 61, 274-284.

Elsner, B., \& Hommel, B. (2001). Effect anticipation and action control. Journal of Experimental Psychology: Human Perception and Performance, 27, 229-240.

Eriksen, B. A., \& Eriksen, C. W. (1974). Effects of noise letters upon the identification of a target letter in a nonsearch task. Perception \& Psychophysics, 16(1), 143-149.

Fan, J., McCandliss, B. D., Sommer, T., Raz, A., \& Posner, M. I. (2002). Testing the efficiency and independence of attentional networks. Journal of Cognitive Neuroscience, 14(3), 340-347.

Fitousi, D. (2013). Mutual information, perceptual independence, and holistic face perception. Attention Perception, \& Psychophysics, $75,983-1000$.

Fitousi, D. (2014). On the internal representation of numerical magnitude and physical size. Experimental Psychology, 61, 149-163.

Fitousi, D. (2015). Composite faces are not processed holistically: Evidence from the Garner and redundant target paradigms. Attention, Perception \& Psychophysics, 77, 2037-2060.
Fitousi, D., \& Algom, D. (2006). Size congruity effects with two-digit numbers: Expanding the number line? Memory \& Cognition, 34(2), 445-457.

Fitousi, D., Shaki, S., \& Algom, D. (2009). The role of parity, physical size, and magnitude in numerical cognition: The SNARC effect revisited. Perception \& Psychophysics, 71(1), 143-155.

Fitousi, D., \& Wenger, M. J. (2013). Variants of independence in the perception of facial identity and expression. Journal of Experimental Psychology: Human Perception, and Performance, 39, 133-155.

Frith, C. D., \& Done, D. J. (1986). Routes to action in reaction time tasks. Psychological Research, 48(3), 169-177.

Garner, W. R. (1969). Speed of discrimination with redundant stimulus attributes. Perception \& Psychophysics, 6, 221-224.

Garner, W. R. (1970). The stimulus in information processing. American Psychologist, 25, 350-358.

Garner, W. R. (1974). The processing of information and structure. Potomac: Erlbaum.

Garner, W. R. (1976). Interaction of stimulus dimensions in concept and choice processes. Cognitive Psychology, 8, 98-123.

Garner, W. R., \& Felfoldy, G. L. (1970). Integrality of stimulus dimensions in various types of information processing. Cognitive Psychology, 1, 225-241.

Garner, W. R., Hake, H. W., \& Eriksen, C. W. (1956). Operationism and the concept of perception. Psychological Review, 63, 149-159.

Garner, W. R., \& Morton, J. (1969). Perceptual independence: Definitions, models, and experimental paradigms. Psychological Bulletin, 72(4), 233-259.

Gevers, W., Caessens, B., \& Fias, W. (2005). Towards a common processing architecture underlying Simon and SNARC effects. European Journal of Cognitive Psychology, 17(5), 659-673.

Gottwald, R. L., \& Garner, W. R. (1972). Effects of focusing strategy on speeded classification with grouping, filtering, and condensation tasks. Perception \& Psychophysics, 11, 179-182.

Gottwald, R. L., \& Garner, W. R. (1975). Filtering and condensation tasks with integral and separable dimensions. Perception \& Psychophysics, 18, 26-28.

Handel, S., \& Imai, S. (1972). The free classification of analyzable and unanalyzable stimuli. Perception \& Psychophysics, 12, 108-116.

Harless, E. (1861). Der Apparat des Willens. Zeitschrift fuer Philosophie und philosophische Kritik, 38, 50-73.

Hedge, A., \& Marsh, N. W. A. (1975). The effect of irrelevant spatial correspondences on two-choice response-time. Acta Psychologica, 39(6), 427-439.

Hillyard, S. A., \& Münte, T. F. (1984). Selective attention to color and location: An analysis with event-related brain potentials. Perception \& Psychophysics, 36(2), 185-198.

Hommel, B. (1993a). Inverting the Simon effect by intention: determinants of direction and extent of effects of irrelevant spatial information. Psychological Research, 5, 270-279.

Hommel, B. (1993b). The relationship between stimulus processing and response selection in the Simon task: evidence for a temporal overlap. Psychological Research, 55, 280-290.

Hommel, B. (1994). Spontaneous decay of response code activation. Psychological Research, 56, 261-268.

Hommel, B. (2004). Coloring an action: intending to produce color events eliminates the Stroop effect. Psychological Research, 68, 74-90.

Hommel, B. (2011). The Simon effect as tool and heuristic. Acta Psychologica, 136(2), 189-202.

Hommel, B., Proctor, R. W., \& Vu, K.-P. L. (2004). A feature-integration account of sequential effects in the Simon task. Psychological Research, 68(1), 1-17.

Hopf, J. M., Boelmans, K., Schoenfeld, M. A., Luck, S. J., \& Heinze, H. J. (2004). Attention to features precedes attention to locations in 
visual search: Evidence from electromagnetic brain responses in humans. The Journal of Neuroscience, 24(8), 1822-1832.

Hyman, R., \& Well, A. (1967). Judgments of similarity and spatial models. Perception \& Psychophysics, 2, 233-248.

Hyman, R., \& Well, A. (1968). Perceptual separability and spatial models. Perception \& Psychophysics, 3, 161-165.

Imai, S. (1966). Classification of sets of stimuli with different stimulus characteristics and numerical properties. Perception \& Psychophysics, 1, 48-54.

Imai, S., \& Garner, W. R. (1965). Discriminability and preference for attributes in free and constrained classification. Journal of Experimental Psychology, 69, 596-608.

Ivanoff, J. (2003). On spatial response code activation in a Simon task. Acta Psychologica, 112(2), 157-179.

James, W. (1890). The principles of psychology (Vol. 2). New York: Dover Publications.

Johnston, J. C., \& Pashler, H. (1990). Close binding of identity and location in visual feature perception. Journal of Experimental Psychology: Human Perception and Performance, 16(4), 843-856.

Kornblum, S. (1994). The way irrelevant dimensions are processed depends on what they overlap with: The case of Stroop- and Simonlike stimuli. Psychological Research, 56, 130-135.

Kornblum, S., Hasbroucq, T., \& Osman, A. (1990). Dimensional overlap: Cognitive basis ofstimulus-response compatibility - a model and taxonomy. Psychological Review, 97, 253-270.

Kornblum, S., Stevens, G. T., Whipple, A., \& Requin, J. (1999). The effects of irrelevant stimuli: 1 . The time course of stimulus-stimulus and stimulus-response consistency effects with Stroop-like stimuli, Simon-like tasks, and their factorial combinations. Journal of Experimental Psychology: Human Perception and Performance, 25(3), 688-714.

Little, D. R., Wang, T., \& Nosofsky, R. M. (2016). Sequence-sensitive exemplar and decision-bound accounts of speeded-classification performance in a modified Garner-tasks paradigm. Cognitive Psychology, 89, 1-38.

Lockhead, G. R. (1966). Effects of dimensional redundancy on visual discrimination. Journal of Experimental Psychology, 72, 95-104.

Lockhead, G. R. (1972). Processing dimensional stimuli: A note. Psychological Review, 79, 410-419.

Lotze, R. H. (1852). Medicinische Psychologie oder die Physiologie der Seele. Leipzig: Weidmann'sche Buchhandlung.

Lu, C. H., \& Proctor, R. W. (1995). The influence of irrelevant location information on performance: A review of the Simon and spatial Stroop effects. Psychonomic Bulletin \& Review, 2(2), 174-207.

Maddox, W. T. (1992). Perceptual and decisional separability. In F. G. Ashby (Ed.), Multidimensional models of perception and cognition (pp. 147-180). Hillsdale: Erlbaum.

Martino, G., \& Marks, L. E. (2000). Cross-modal interaction between vision and touch: The role of synesthetic correspondence. Perception, 29, 745-754.

Melara, R. D., \& Algom, D. (2003). Driven by information: A tectonic theory of Stroop effects. Psychological Review, 110, 422-471.

Melara, R. D., \& Marks, L. E. (1990). Perceptual primacy of dimensions: Support for a model of dimensional interaction. Journal of Experimental Psychology: Human Perception and Performance, $16,398-414$

Melara, R. D., \& Mounts, J. R. (1993). Selective attention to Stroop dimensions: Effects of baseline discriminability, response mode, and practice. Memory \& Cognition, 21, 627-645.

Melara, R. D., Wang, H., Vu, K. P. L., \& Proctor, R. W. (2008). Attentional origins of the Simon effect: Behavioral and electrophysiological evidence. Brain Research, 1215, 147-159.

Milner, A. D., \& Goodale, M. A. (1995). The visual brain in action (Oxford Psychology Series, No. 27). New York: Oxford University Press.
Nicoletti, R., \& Umiltá, C. (1989). Splitting visual space with attention. Journal of Experimental Psychology: Human Perception and Performance, 15(1), 164-169.

Nicoletti, R., \& Umiltà, C. (1994). Attention shifts produce spatial stimulus codes. Psychological Research, 56(3), 144-150.

O'Leary, M. J., \& Barber, P. J. (1993). Interference effects in the Stroop and Simonparadigms. Journal of Experimental Psychology: Human Perception and Performance, 19(4), 830-844.

Pansky, A., \& Algom, D. (1999). Stroop and Garner effects in comparative judgment of numerals: The role of attention. Journal of Experimental Psychology: Human Perception and Performance, $25,39-59$.

Pansky, A., \& Algom, D. (2002). Comparative judgment of numerosity and numerical magnitude: Attention preempts automaticity. Journal of Experimental Psychology: Learning, Memory \& Cognition, 28, 259-274.

Patching, G. R., \& Quinlan, P. T. (2002). Garner and congruence effects in the speeded classification of bimodal signals. Journal of Experimental Psychology: Human Perception and Performance, $28,755-775$.

Pomerantz, J. R. (1983). Global and local precedence: Selective attention in form and motion perception. Journal of Experimental Psychology: General, 112, 516-540.

Pomerantz, J. R. (1991). The structure of stimulus configurations: stimulus versus subject contributions. In G. R. Lockhead \& J. R. Pomerantz (Eds.), The perception of structure: Essays in honor of Wendell R. Garner (pp. 195-210). Washington: APA.

Pomerantz, J. R., \& Garner, W. R. (1973). Stimulus configuration in selective attention tasks. Perception \& Psychophysics, 14, 565-569.

Pomerantz, J. R., Pristach, E. A., \& Carson, C. E. (1989). Attention and object perception. In B. E. Shepp \& S. Ballesteros (Eds.), Object perception: Structure and process (pp. 53-89). Hillsdale: Erlbaum.

Posner, M. I. (1980). Orienting of attention. Quarterly Journal of Experimental Psychology, 32, 3-25.

Pratte, M. S., Rouder, J. N., Morey, R. D., \& Feng, C. (2010). Exploring the differences in distributional properties between Stroop and Simon effects using delta plots. Attention, Perception, \& Psychophysics, 72(7), 2013-2025.

Prinzmetal, W., McCool, C., \& Park, S. (2005). Attention: Reaction time and accuracy reveal different mechanisms. Journal of Experimental Psychology: General, 134(1), 73-92.

Proctor, R. W., \& Lu, C. (1999). Processing irrelevant location information: Practice and transfer effects in choice-reaction tasks. Memory \& Cognition, 27(1), 63-77.

Ratcliff, R. (1978). A theory of memory retrieval. Psychological Review, $85(2), 59-108$

Ridderinkhof, R. K. (2002a). Activation and suppression in conflict tasks: empirical clarification through distributional analyses. In W. Prinz \& B. Hommel (Eds.), Attention and Performance XIX: Mechanisms in Perception and Action (pp. 494-519). Oxford: Oxford University Press.

Ridderinkhof, R. K. (2002b). Micro- and macro-adjustments of task set: activation and suppression in conflict tasks. Psychological Research, 66(4), 312-323.

Rizzolatti, G., Riggio, L., Dascola, I., \& Umiltà, C. (1987). Reorienting of attention acrossthe horizontal and vertical meridians: Evidence in favor of a premotor theory ofattention. Neuropsychologia, 25, 3140.

Roswarski, T. E., \& Proctor, R. W. (1996). Multiple spatial codes and temporal overlap in choice-reaction tasks. Psychological Research, 59(3), 196-211.

Sabri, M., Melara, R. D., \& Algom, D. (2001). A confluence of contexts: Asymmetric versus global failures of selective attention to Stroop dimensions. Journal of Experimental psychology: Human Perception and Performance, 27(3), 515-537. 
Sanders, A. F. (1967). Some aspects of reaction processes. Acta Psychologica, 27, 115-130.

Shalev, L., \& Algom, D. (2000). Stroop and Garner effects in and out of Posner's beam: Reconciling two conceptions of selective attention. Journal of Experimental Psychology: Human Perception and Performance, 26(3), 997-1017.

Simon, J. R. (1969). Reactions towards the source of stimulation. Journal of Experimental Psychology, 81, 174-176.

Simon, J. R., Acosta, E., Mewaldt, S. P., \& Speidel, C. R. (1976). The effect of an irrelevant directional cue on choice reaction time: duration of the phenomenon and its relation to stages of processing. Perception \& Psychophysics, 19(1), 16-22.

Simon, J. R., Hinrichs, J. V., \& Craft, J. L. (1970). Auditory S-R compatibility: Reaction time as a function of ear-hand correspondence and ear-response-location correspondence. Journal of Experimental Psychology, 86, 97-102.

Simon, J. R., \& Rudell, A. P. (1967). Auditory S-R compatibility: The effect of an irrelevant cue on information processing. Journal of Applied Psychology, 51, 300-304.

Simon, J. R., \& Small, A. M., Jr. (1969). Processing auditory information: Interference from an irrelevant cue. Journal of Applied Psychology, 53, 433-435.

Sokolov, E. N. (1963). Perception and the conditioned reflex. Oxford: Pergamon Press.

Stroop, J. R. (1935). Studies of interference in serial verbal reactions. Journal of experimental psychology, 18(6), 643-662.

Stürmer, B., Leuthold, H., Soetens, E., Schröter, H., \& Sommer, W. (2002). Control over location-based response activation in the Simon task: Behavioral and electrophysiological evidence. Journal of Experimental Psychology: Human Perception and Performance, 28, 1345-1363.

Tagliabue, M., Zorzi, M., Umiltà, C., \& Bassignani, F. (2000). The role of long-term-memory and short-term-memory links in the Simon effect. Journal of Experimental Psychology: Human Perception and Performance, 26(2), 648--670.

Toth, J. P., Levine, B., Stuss, D. T., Oh, A., Winocur, G., \& Meiran, N. (1995). Dissociation of processes underlying spatial SR compatibility: Evidence for the independent influence of what and where. Consciousness and Cognition, 4(4), 483-501.

Treccani, B., Umiltà, C., \& Tagliabue, M. (2006). Simon effect with and without awareness of the accessory stimulus. Journal of Experimental Psychology: Human Perception and Performance, 32(2), 268-286.

Treisman, A. M., \& Gelade, G. (1980). A feature-integration theory of attention. Cognitive Psychology, 12(1), 97-136.

Treue, S., \& Trujillo, J. C. M. (1999). Feature-based attention influences motion processing gain in macaque visual cortex. Nature, 399(6736), 575-579.

Tsal, Y., \& Lamy, D. (2000). Attending to an object's color entails attending to its location: Support for location-special views of visual attention. Perception \& Psychophysics, 62(5), 960-968.
Tsal, Y., \& Lavie, N. (1988). Attending to color and shape: The special role of location in selective visual processing. Perception \& Psychophysics, 44(1), 15-21.

Tsal, Y., \& Lavie, N. (1993). Location dominance in attending to color and shape. Journal of Experimental Psychology: Human Perception and Performance, 19(1), 131-139.

Umiltà, C. (2004). The Simon effect: Introductory remarks. Psychological Research, 56, 127-129.

Valle-Inclán, F., Hackley, S. A., \& De Labra, C. (2003). Stimulusresponse compatibility between stimulated eye and response location: Implications for attentional accounts of the Simon effect. Psychological Research, 67(4), 240-243.

Valle-Inclán, F., \& Redondo, M. (1998). On the automaticity of ipsilateral response activation in the Simon effect. Psychophysiology, 35(4), 366-371.

Vallesi, A., \& Umiltà, C. A. (2009). Decay of stimulus spatial code in horizontal and vertical Simon tasks. The Journal of General Psychology: Experimental, Psychological, and Comparative Psychology, 136(4), 350-373.

Van Leeuwen, C., \& Bakker, L. (1995). Stroop can occur without Garner interference: Strategic and mandatory influences in multidimensional stimuli. Perception \& Psychophysics, 57, 379-392.

Wallace, R. J. (1971). SR compatibility and the idea of a response code. Journal of Experimental Psychology, 88(3), 354-360.

Wascher, E., Schatz, U., Kuder, T., \& Verleger, R. (2001). Validity and boundary conditions of automatic response activation in the Simon task. Journal of Experimental Psychology: Human Perception and Performance, 27(3), 731-751.

Wolfe, J. M. (1994). Guided search 2.0 a revised model of visual search. Psychonomic Bulletin \& Review, 1(2), 202-238.

Wühr, P. (2006). Response preparation modulates interference from irrelevant spatial information. Acta Psychologica, 122(2), 206-220.

Wühr, P., \& Ansorge, U. (2005). Exploring trial-by-trial modulations of the Simon effect. The Quarterly Journal of Experimental Psychology, 58(4), 705-731.

Wühr, P., \& Ansorge, U. (2007). A Simon effect in memory retrieval: Evidence for the response-discrimination account. Psychonomic bulletin \& review, 14(5), 984-988.

Wühr, P., \& Biebl, R. (2011). The role of working memory in spatial S-R correspondence effects. Journal of Experimental Psychology: Human Perception and Performance, 37(2), 442-454.

Zhang, J., \& Kornblum, S. (1997). Distributional analysis and De Jong, Liang, and Lauber's (1994) dual-process model of the Simon effect. Journal of Experimental Psychology: Human Perception and Performance, 23(5), 1543-155.

Zhang, W., \& Luck, S. J. (2009). Feature-based attention modulates feedforward visual processing. Nature Neuroscience, 12(1), 24-25.

Zorzi, M., \& Umiltá, C. (1995). A computational model of the Simon effect. Psychological Research, 58(3), 193-205. 